NASA/TM-2007-214935

\title{
Shock Characteristics Measured Upstream of Both a Forward-Swept and an Aft-Swept Fan
}

Gary G. Podboy, Martin J. Krupar, and Daniel L. Sutliff

Glenn Research Center, Cleveland, Ohio

Csaba Horvath

Budapest University of Technology and Economics, Budapest, Hungary 


\section{NASA STI Program . . . in Profile}

Since its founding, NASA has been dedicated to the advancement of aeronautics and space science. The NASA Scientific and Technical Information (STI) program plays a key part in helping NASA maintain this important role.

The NASA STI Program operates under the auspices of the Agency Chief Information Officer. It collects, organizes, provides for archiving, and disseminates NASA's STI. The NASA STI program provides access to the NASA Aeronautics and Space Database and its public interface, the NASA Technical Reports Server, thus providing one of the largest collections of aeronautical and space science STI in the world. Results are published in both non-NASA channels and by NASA in the NASA STI Report Series, which includes the following report types:

- TECHNICAL PUBLICATION. Reports of completed research or a major significant phase of research that present the results of NASA programs and include extensive data or theoretical analysis. Includes compilations of significant scientific and technical data and information deemed to be of continuing reference value. NASA counterpart of peer-reviewed formal professional papers but has less stringent limitations on manuscript length and extent of graphic presentations.

- TECHNICAL MEMORANDUM. Scientific and technical findings that are preliminary or of specialized interest, e.g., quick release reports, working papers, and bibliographies that contain minimal annotation. Does not contain extensive analysis.

- CONTRACTOR REPORT. Scientific and technical findings by NASA-sponsored contractors and grantees.
- CONFERENCE PUBLICATION. Collected papers from scientific and technical conferences, symposia, seminars, or other meetings sponsored or cosponsored by NASA.

- SPECIAL PUBLICATION. Scientific, technical, or historical information from NASA programs, projects, and missions, often concerned with subjects having substantial public interest.

- TECHNICAL TRANSLATION. Englishlanguage translations of foreign scientific and technical material pertinent to NASA's mission.

Specialized services also include creating custom thesauri, building customized databases, organizing and publishing research results.

For more information about the NASA STI program, see the following:

- Access the NASA STI program home page at http://www.sti.nasa.gov

- E-mail your question via the Internet to help@sti.nasa.gov

- Fax your question to the NASA STI Help Desk at 301-621-0134

- Telephone the NASA STI Help Desk at 301-621-0390

- Write to: NASA Center for AeroSpace Information (CASI) 7115 Standard Drive Hanover, MD 21076-1320 


\section{Shock Characteristics Measured Upstream of Both a Forward-Swept and an Aft-Swept Fan}

Gary G. Podboy, Martin J. Krupar, and Daniel L. Sutliff

Glenn Research Center, Cleveland, Ohio

Csaba Horvath

Budapest University of Technology and Economics, Budapest, Hungary

Prepared for

ASME Turbo Expo 2007

sponsored by the American Society of Mechanical Engineers and the International Gas Turbine Institute Montreal, Canada, May 14-17, 2007

National Aeronautics and

Space Administration

Glenn Research Center

Cleveland, Ohio 44135 


\section{Acknowledgments}

The authors wish to thank Mr. Thomas Gyekenyesi, the lead test engineer during this test, and the rest of the technical support staff at the 9- by 15-Foot Low-Speed Wind Tunnel. Thanks also to Mr. Devin Podboy for reducing and plotting the shroud unsteady pressure measurements presented in this report.

Trade names and trademarks are used in this report for identification only. Their usage does not constitute an official endorsement, either expressed or implied, by the National Aeronautics and Space Administration.

This work was sponsored by the Fundamental Aeronautics Program at the NASA Glenn Research Center.

Level of Review: This material has been technically reviewed by technical management.

Available from

NASA Center for Aerospace Information 7115 Standard Drive

Hanover, MD 21076-1320
National Technical Information Service 5285 Port Royal Road Springfield, VA 22161 


\title{
Shock Characteristics Measured Upstream of Both a Forward-Swept and an Aft-Swept Fan
}

\author{
Gary G. Podboy, Martin J. Krupar, and Daniel L. Sutliff \\ National Aeronautics and Space Administration \\ Glenn Research Center \\ Cleveland, Ohio 44135 \\ Csaba Horvath \\ Budapest University of Technology and Economics \\ Budapest, Hungary
}

\begin{abstract}
Three different types of diagnostic data-blade surface flow visualization, shroud unsteady pressure, and laser Doppler velocimeter (LDV) - were obtained on two fans, one forward-swept and one aft-swept, in order to learn more about the shocks which propagate upstream of these rotors when they are operated at transonic tip speeds. Flow visualization data are presented for the forward-swept fan operating at $13831 \mathrm{rpm}_{\mathrm{C}}$ and for the aft-swept fan operating at 12500 and $13831 \mathrm{rpm}_{\mathrm{c}}$ (corresponding to tip rotational Mach numbers of 1.07 and 1.19, respectively). The flow visualization data identify where the shocks occur on the suction side of the rotor blades. These data show that at the takeoff speed, $13831 \mathrm{rpm}_{\mathrm{c}}$, the shocks occurring in the tip region of the forward-swept fan are further downstream in the blade passage than with the aftswept fan. Shroud unsteady pressure measurements were acquired using a linear array of 15 equally-spaced pressure transducers extending from two tip axial chords upstream to 0.8 tip axial chords downstream of the static position of the tip leading edge of each rotor. Such data are presented for each fan operating at one subsonic and five transonic tip speeds. The unsteady pressure data show relatively strong detached shocks propagating upstream of the aft-swept rotor at the three lowest transonic tip speeds, and weak, oblique pressure disturbances attached to the tip of the aft-swept fan at the two highest transonic tip speeds. The unsteady pressure measurements made with the forward-swept fan do not show strong shocks propagating upstream of that rotor at any of the tested speeds. A comparison of the forward-swept and aftswept shroud unsteady pressure measurements indicates that at any given transonic speed the pressure disturbance just upstream of the tip of the forward-swept fan is much weaker than that of the aft-swept fan. The LDV data suggest that at 12500 and $13831 \mathrm{rpm}_{\mathrm{c}}$, the forward-swept fan swallowed the passage shocks occurring in the tip region of the blades, whereas the aft-swept fan did not. Due to this difference, the flows just upstream of the two fans were found to be quite different at both of these transonic speeds. Nevertheless, despite distinct differences just upstream of the two rotors, the two fan flows were much more alike about one axial blade chord further upstream. As a result, the LDV data suggest that
\end{abstract}

it is unwise to attempt to determine the effect that the shocks have on far field noise by focusing only on measurements (or CFD predictions) made very near the rotor. Instead, these data suggest that it is important to track the shocks throughout the inlet.

\section{Introduction}

Narrow band noise spectra of high bypass ratio turbofan engines operating at subsonic fan tip speeds normally contain tones at harmonics of the fan blade passing frequency (BPF). If the rotational speed of the fan is increased so that the relative tip speed becomes supersonic, extra tones normally appear in the spectra at multiples of the shaft rotational speed (multiples of the once-per-rev frequency). These extra tones have been attributed to blade-to-blade differences in the shocks propagating upstream of the fan blades. These bladeto-blade differences in the shocks occur due to slight differences in the blades and/or to differences in how the blades "seat" into the hub when they are spun up to speed. The differences in the shocks generate a pressure pattern upstream of the rotor which contains features which repeat on a onceper-revolution basis. Hence, a frequency spectrum computed from such a pressure field will contain harmonics of the onceper-rev frequency. Any such tones which occur at integer multiples of the once-per-rev frequency which are not also integer multiples of the blade passing frequency are known as multiple pure tones (MPTs).

One approach to reducing multiple pure tone noise focuses on attenuating the noise after it has been produced. There are a number of methods of doing this. One is to absorb the sound using an acoustic liner or splitter in the inlet duct (ref. 1). Unfortunately, adding these sound suppression devices can add weight and length to the inlet and/or reduce aerodynamic efficiency (ref. 2). Another method is to design the inlet so that the shock waves which produce the MPT noise are attenuated before they propagate out the inlet. The shocks can be attenuated by designing the inlet so that the flow speed at the inlet throat approaches Mach 1 . As explained by Prasad et al., "the larger axial Mach number prolongs the residence time of the shocks in the duct, permitting them to decay further" (ref. 3). 
The second approach involves designing the fan blades so that the shocks which normally form at high rotor speeds are reduced in strength or prevented from propagating into the inlet. This was the approach taken in a NASA-sponsored program conducted jointly by Bolt, Beranek and Newman Inc. and AVCO Lycoming (ref. 2) during the 1970's. The highspeed QF-12 fan was developed under this program. The QF12 blades had compound sweep so that the flow normal to the leading edges was subsonic over its entire operating range. This design was effective in preventing the formation of most of the upstream propagating shocks normally associated with high speed operation and did result in reduced MPT noise; however, it did not meet aerodynamic performance goals.

More recently, the swept-rotor concept was investigated once again, this time as part of NASA's Advanced Subsonic Technology (AST) Noise Reduction Program. Two different fan models-one forward-swept and one aft-swept-were tested at the NASA Glenn 9 by $15 \mathrm{ft}$ Wind Tunnel. Both models were designed and built by Honeywell Engines and Systems (ref. 4). The aft-swept design is a scale model of Honeywell's TFE731-60 engine. At the time of the test, the forward-swept fan was known as the Quiet High Speed Fan (QHSF). Due to operability problems with this fan, however, Honeywell has since developed a new fan that has less forward sweep than the original design. The new design is now referred to as the Quiet High Speed Fan II (QHSF II), and it's predecessor, the forward-swept fan which is discussed in this report, is called the Quiet High Speed Fan I (QHSF I).

This test was conducted in order to demonstrate that the forward-swept model would produce less noise than the aftswept model when operating at high speeds. The goal was for the forward-swept model to be 6 EPNdB quieter than the aftswept design when operating near the takeoff condition. One of the primary reasons why the forward-swept model was expected to generate less overall noise was that it was designed to create less multiple pure tone noise. The forwardswept fan was expected to generate less MPT noise since it was designed to swallow the shocks occurring within the tip region of the rotor when operating at the take-off condition, whereas the aft-swept fan was not. It turns out, however, that although the forward-swept model did meet the noise reduction goal, the reasons that it did had little to do with multiple pure tone noise. The multiple pure tone levels of the two models were actually quite comparable. They were also much lower than the tones occurring at the blade passing frequency (BPF) and its harmonics. Acoustic mode measurements made using a rotating microphone rake in the inlet indicate that most of this BPF noise was due to rotor/strut interaction. The main reason that the forward-swept model met the noise reduction goal is that it produced less rotor-strut interaction tone noise. For more information on the acoustic results from this test see the papers by Dittmar et al. (ref. 5) and Heidelberg (ref. 6). The aerodynamic performance of these two models is discussed in a paper by Fite (ref. 7).

In addition to the acoustic and aerodynamic performance measurements made during this test, three different types of flow field diagnostic data were also obtained: blade surface flow visualization, unsteady pressure measurements in the outer duct wall above and upstream of the blade tips, and laser LDV. Most of these measurements were made in order to learn more about the shocks which propagate upstream of the rotors when the fans are operated at transonic tip speeds. As mentioned above, these shocks are responsible for generating multiple pure tone noise, and prior to the test it was anticipated that these two fans would generate different levels of MPT noise. These diagnostic data were obtained to help explain the anticipated differences in MPT noise.

The purpose of this paper is to present some of the flow field diagnostic data that were obtained during this test. The blade surface flow visualization data presented herein provide information regarding where the shocks were located on the suction surface of the rotor blades. The shroud unsteady pressure measurements show both the location of the shocks relative to the tip leading edge of the aft-swept blades and the extent to which the amplitude of the pressure disturbance upstream of the tip of forward-swept fan is reduced relative to that of the aft-swept. The LDV data show that the strong tip shocks were swallowed with forward-swept fan, but not with the aft-swept fan, when operating near the take-off speed. The LDV data also illustrate how the flow perturbations generated by the fans decay as they propagate upstream of the rotors.

\section{Nomenclature}

$\begin{array}{ll}\mathrm{M} & \text { Mach number } \\ \mathrm{M}_{\text {rel }} & \begin{array}{l}\text { Relative Mach number } \\ N\end{array} \\ N_{c} & \text { Mechanical fan speed, rpm } \\ & \text { Corrected fan speed, } \frac{N}{\sqrt{\theta}} \\ N P_{c} & \quad \text { Percent of corrected fan design speed, } \frac{N_{C}}{N_{d p}} \bullet 100, \% \\ T_{o} & \text { Total temperature, }{ }^{\circ} \mathrm{R} \\ \theta & \quad \text { Temperature correction to standard day conditions, } \\ & T_{o} / 518.67^{\circ} \mathrm{R}\end{array}$

Subscripts

$\begin{array}{ll}r e l & \text { Relative } \\ c & \text { Corrected condition } \\ d p & \text { Design point }\end{array}$

\section{Research Instrumentation}

\section{Test Model}

Figure 1 shows the 22-in. (55.9 cm) diameter turbofan model installed in the test section of the NASA Glenn 9 by $15 \mathrm{ft}$ Wind Tunnel. The model is shown here in the 


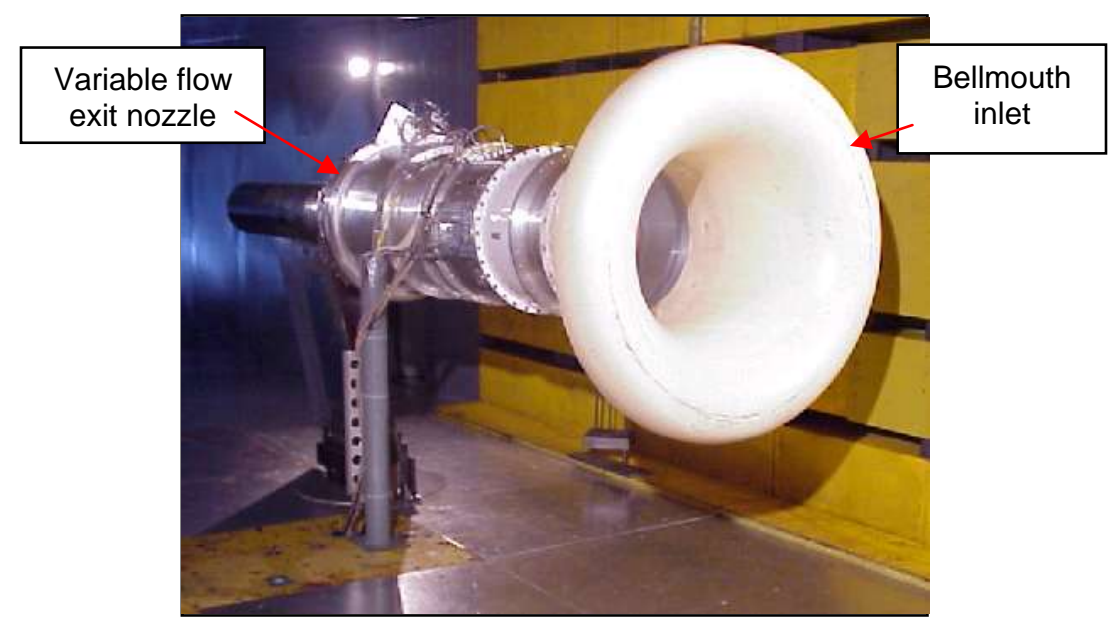

Figure 1.-Turbofan model installed in the test section of the NASA Glenn 9 by $15 \mathrm{ft}$ Wind Tunnel.

"performance" configuration, with a bellmouth inlet and variable flow exit nozzle (VFEN) installed. This is the configuration used during the diagnostic testing, except that the VFEN shown in the photo was replaced with a flight (fixed area) nozzle.

TABLE 1.-FORWARD AND AFT-SWEPT FAN DESIGN PARAMETERS $\left[\mathrm{NP}_{\mathrm{C}}=100 \%\right]$

\begin{tabular}{|l|l|}
\hline Number of blades & 22 \\
\hline Number of vanes & 52 \\
\hline Fan diameter & $22 \mathrm{in} .(0.559 \mathrm{~m})$ \\
\hline Corrected tip speed & $1474 \mathrm{ft} / \mathrm{s}(449.3 \mathrm{~m} / \mathrm{s})$ \\
\hline Corrected fan rotational speed & $15357 \mathrm{rpm}{ }_{\mathrm{c}}$ \\
\hline Corrected fan weight flow & $98.9 \mathrm{lbm} / \mathrm{s}(44.9 \mathrm{~kg} / \mathrm{s})$ \\
\hline Stage pressure ratio & 1.82 \\
\hline Bypass ratio & 3.83 \\
\hline Fan hub-to-tip radius ratio & 0.35 \\
\hline
\end{tabular}

Table 1 shows some of the design parameters of the two fans used in this test program. The rotors and stators used during the test are shown in figure 2. The aft-swept rotor was tested with aft-swept stators; the forward-swept rotor was tested with aft-swept stators that were leaned in the tip region. The aft-swept rotor/aft-swept stator combination represents a scale model of the fan stage found in the Honeywell TFE73160 engine. This stage was chosen as an example of a modern, conventional turbofan design. As such, it was to serve as a baseline model with which the more unconventional forwardswept model could be compared. The forward-swept fan, known as the Quiet High Speed Fan I (QHSF I), was designed to produce less fan noise while maintaining or improving on the performance characteristics of the aft-swept model. During the aerodynamic performance phase of this test it was determined that the forward-swept model outperformed the aft-swept model at the design point (cruise) operating speed of $15357 \mathrm{rpm}_{\mathrm{c}}$ in terms of fan pressure ratio (1.764 vs. 1.755), mass flow (98.28 vs. 97.97 lbm/s (44.58 vs. $44.44 \mathrm{~kg} / \mathrm{s})$ ), and peak adiabatic efficiency (85.9 vs. 83.3 percent). However, problems arose when the forward-swept model was operated near 75 percent of the design speed. At this speed the operability margin of the forward-swept fan approached 0 percent. In contrast, the aft-swept design maintained sufficient operability margin throughout the operating range. For more information regarding the aerodynamic performance results see (ref. 7).

\section{Blade Surface Flow Visualization}

The blade surface flow visualization data were a byproduct of the LDV testing. Over the course of an LDV test run, some of the polystyrene latex particles used as LDV seed accumulate on the solid surfaces within the model. When a rotor is run at transonic speeds, the abrupt changes in flow velocity associated with the shocks in the flow cause a significant build-up of seed on the blade suction surface downstream of the shocks, but relatively little build-up upstream. Consequently, if the seed is allowed to flow in the tunnel only when the fan is operating at a constant transonic test speed then the seed pattern on the blades traces out a line corresponding to where the shock occurs on the blade suction surface.

\section{Shroud Unsteady Pressure Measurements}

Shroud unsteady pressure measurements were obtained using a linear array of high response, absolute pressure transducers embedded in the shroud wall over and upstream of the tip of each rotor. A single row of fifteen Kulite model 06225A transducers were installed for each fan. The schematics provided in parts $a$ and $b$ of figure 3 show the locations of the pressure transducers relative to the static position of the aft- 
(a) Side view of the aft-swept fan model.

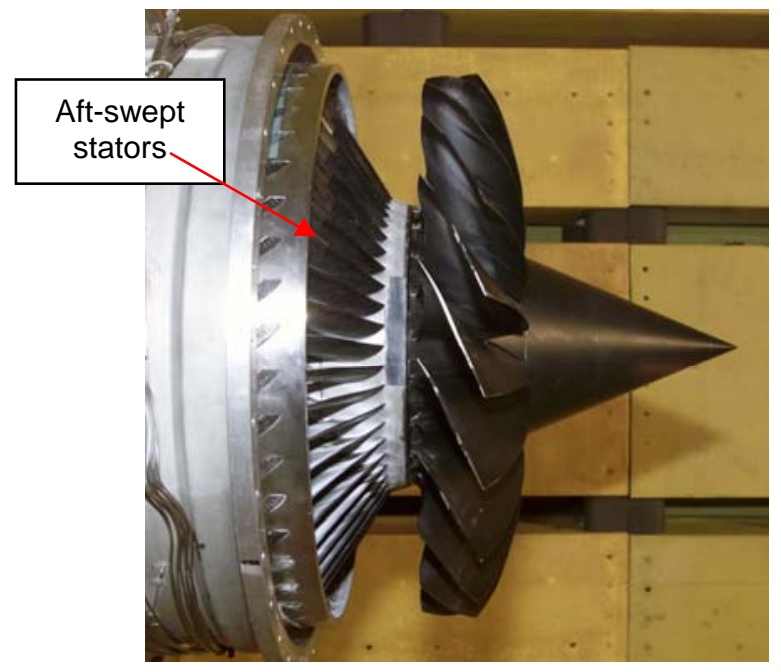

(c) Swept stators tested with the aft-swept rotor.

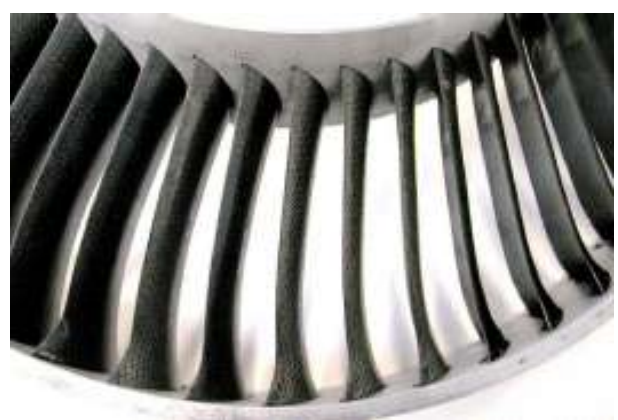

(b) Side view of the forward-swept fan model.

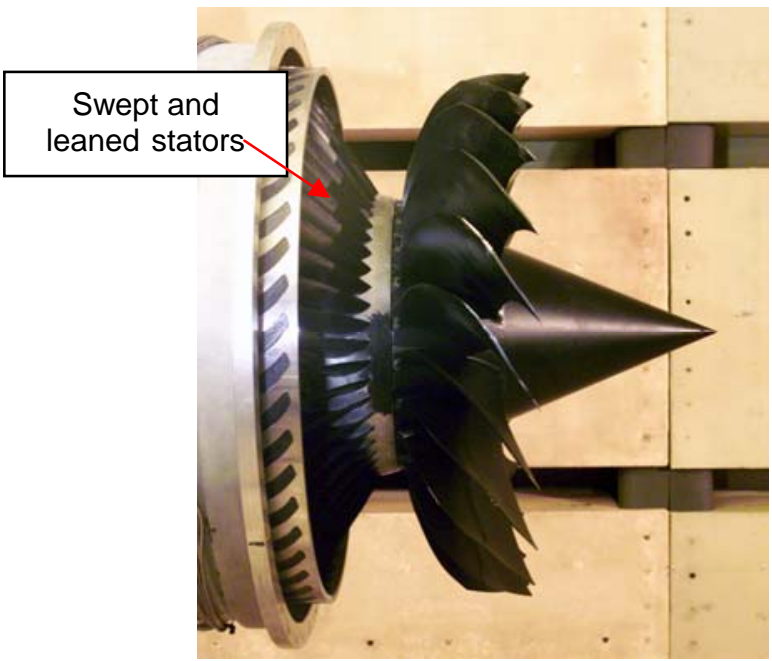

(d) Swept and leaned stators tested with the forward-swept fan.

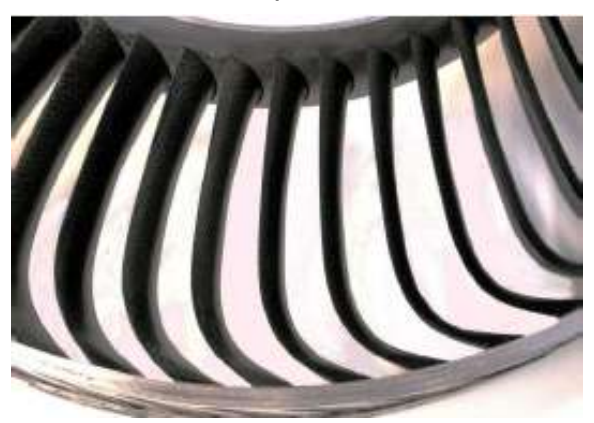

Figure 2.-Photographs of the rotors and stators that were tested.

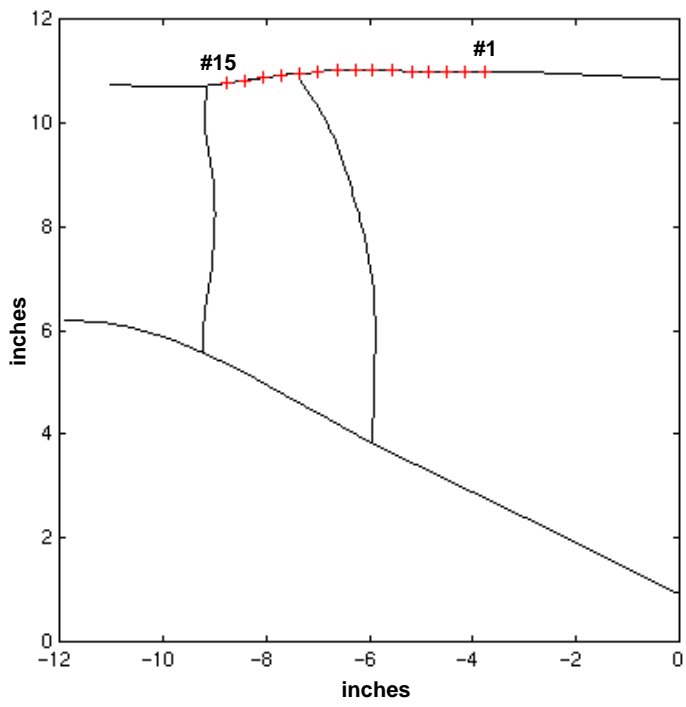

(a) Aft-swept rotor

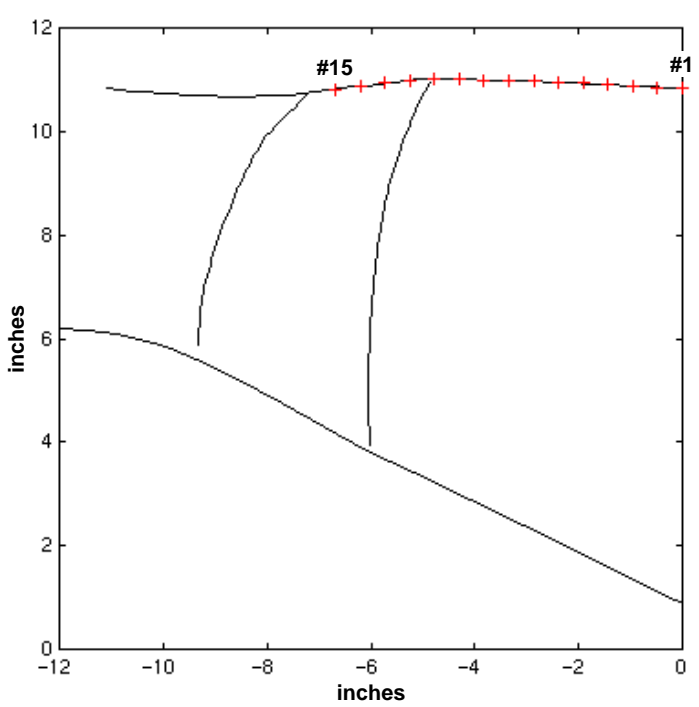

(b) Forward-swept rotor

Figure 3.-Schematics illustrating the locations of the unsteady pressure transducers relative to the aft-swept (left) and forward-swept fans (right). 
swept, and forward-swept rotors, respectively. The coordinate system indicated on these schematics is the same as that used later in the presentation of the LDV data. The pressure transducers were equally spaced and extended from to two tip axial chords upstream to 0.8 tip axial chords downstream of the static position of the tip leading edge of each rotor.

The output of the transducers was recorded using a Nicolet Odyssey OD-200, 16-channel high-speed data acquisition system. The data were sampled synchronously using a 144toothed gear mounted on the rotor shaft as the data system clock signal (e.g., external sampling). This allowed the exact same number of measurements to be recorded for each revolution of the rotor, 144 . This made it relatively easy to compute ensemble averages from the data of different revolutions.

\section{LDV}

In order to obtain the LDV data it was necessary to place part of the LDV system inside the wind tunnel next to the model. Figure 4 shows a photograph of some of the LDV hardware. This photo shows LDV optics mounted onto a vertical breadboard which, in turn, were mounted onto a traverse system. The traverse system was used to move the LDV probe volume axially and radially inside the model. Other parts of the LDV system, including the laser, were located outside the test section. The laser beams were brought into the tunnel via fiber optic cables. The set-up shown here allowed two components of velocity - axial and tangential - to be measured simultaneously. Radial velocities were not measured during this test.

The contour of the internal flow path was not the same for the two fans, therefore two different windows had to be made to permit optical access to the internal flow. These two windows are shown in figure 5 . The window shown at the top of the figure was used during testing of the forward-swept fan; that shown at the bottom was used with the aft-swept rotor. The window glass was slumped in a furnace so that the window contour would conform to the flow path of the model with which it was used. For each of these windows, the upstream edge of the glass was at the same physical axial location relative to the rest of the model hardware. Therefore, the location of the upstream edge of the glass (highlighted in the photos) was chosen as an axial reference location during

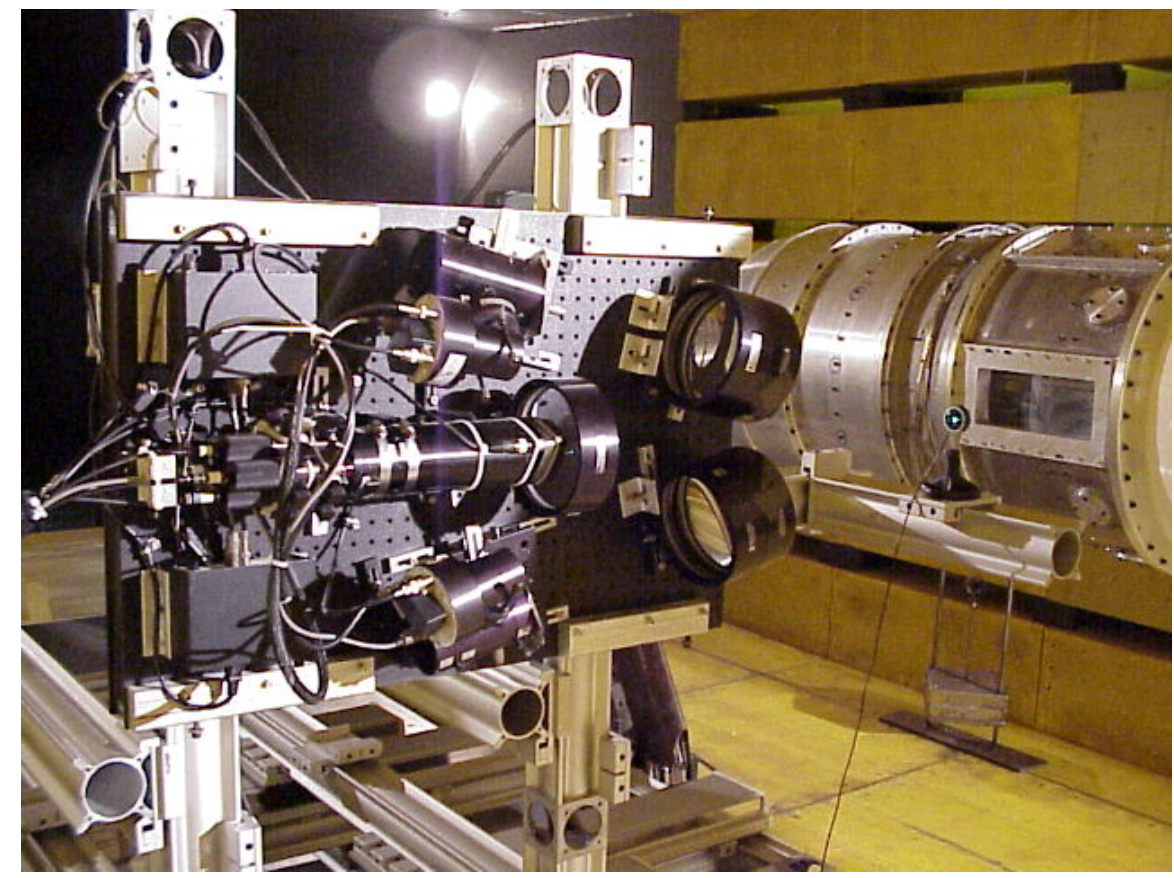

Figure 4.-Photograph of LDV optics mounted to traverse table located on the side of the turbofan model in the NASA Glenn 9 by $15 \mathrm{ft}$ Wind Tunnel. 

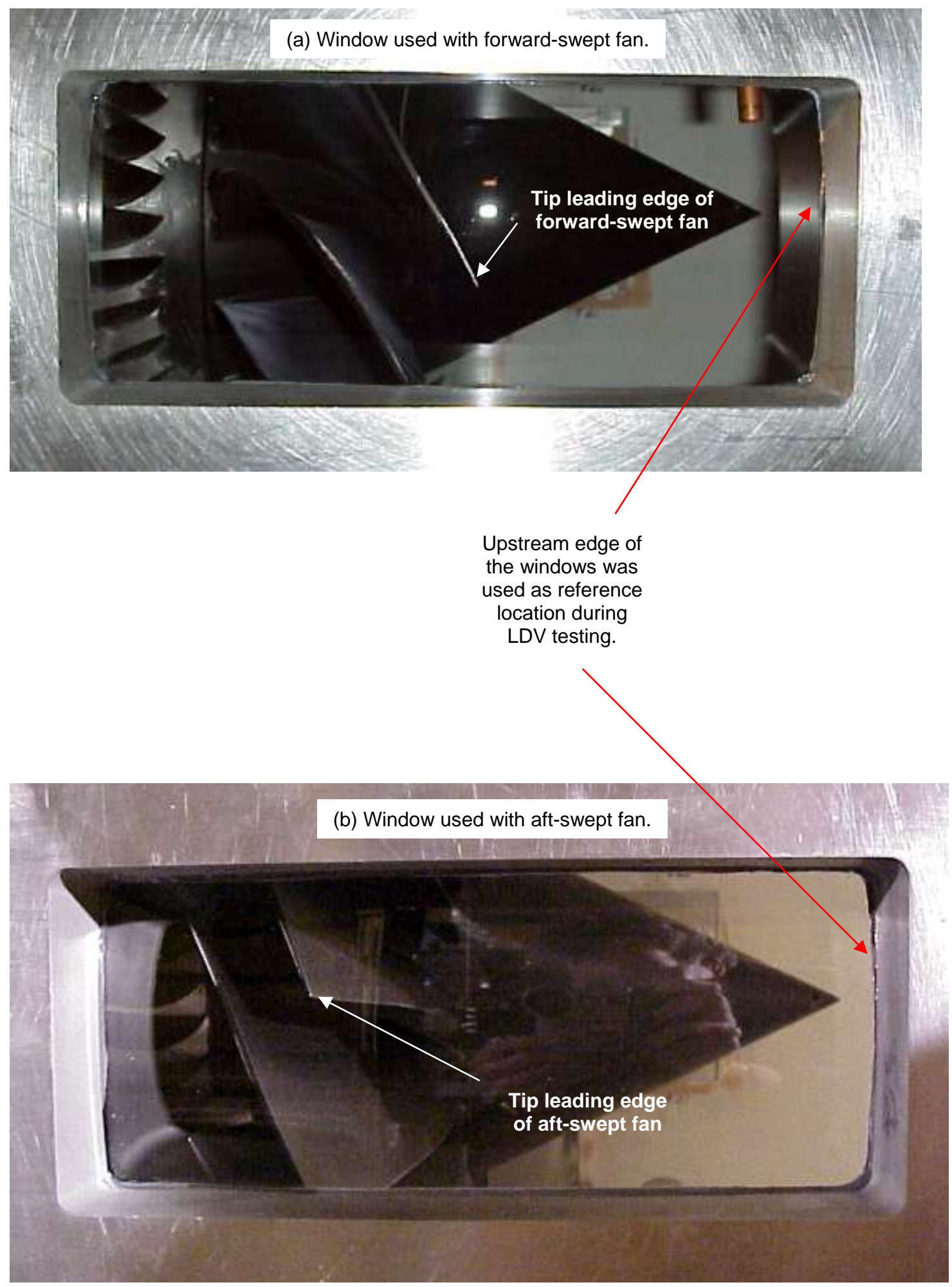

Figure 5.-Windows used to obtain optical access to the internal model flows. 
the LDV testing. This axial location was chosen as the origin of the LDV reference frame such that locations downstream of the edge were considered to be in the negative $\mathrm{x}$ direction. The static position of the tip leading edge of the forward-swept blades was 4.85 in. $(12.3 \mathrm{~cm})$ downstream of the window edge (i.e., at $x=-4.85$ in.), while that of the aft-swept blades was 7.35 in. (18.7 cm) downstream (at $x=-7.35$ in.).

Data were obtained via constant-axial and constant-radial traverses of the LDV probe volume as shown in figure 6. LDV data were obtained at the three different rotor speeds shown in table 2. In the discussion of the blade surface flow visualization and the LDV data, these three speeds will be referred to as the "low," "mid," and "high" speeds. The "high" speed corresponds to the take-off condition, which is lower than the design (cruise) speed. Parts (a), (b), and (c) of figure 6 show the measurement locations corresponding to the rotor speeds shown in table 2 .

TABLE 2.-LDV TEST OPERATING CONDITIONS

\begin{tabular}{|c|c|c|c|c|}
\hline $\begin{array}{c}\text { Condition, } \\
\text { speed }\end{array}$ & $\begin{array}{c}\text { Corrected, } \\
\mathrm{rpm}\end{array}$ & $\begin{array}{c}\text { Corrected tip speed, } \\
\mathrm{ft} / \mathrm{s}(\mathrm{m} / \mathrm{s})\end{array}$ & $\begin{array}{c}\mathrm{NP}_{\mathrm{c}}, \\
\%\end{array}$ & $\begin{array}{c}\text { Rotational } \\
\text { tip, } \\
\mathrm{M}\end{array}$ \\
\hline Low & 9510 & $913(278)$ & 61.9 & 0.82 \\
\hline Mid & 12500 & $1200(366)$ & 81.4 & 1.07 \\
\hline High & 13831 & $1328(405)$ & 90.1 & 1.19 \\
\hline
\end{tabular}

The individual velocity measurements made with the LDV system were sorted into circumferential bins around the rotor using shaft angle encoders fed with the once-per-rev signal of the rotor. These encoders segmented the $360^{\circ}$ of rotor revolution occurring between two consecutive once-per-rev pulses into 1100 bins (50 bins per blade passage). Each time a velocity measurement was made, the encoder output was sampled to determine the number of bins generated since the occurrence of the previous once-per-rev pulse. The velocity and corresponding bin number were then stored in the computer as a data pair.

Data were acquired at each measurement location over many rotor revolutions until either a preset number of measurements had been acquired on the two LDV channels, or until the maximum time allotted for the data acquisition had elapsed. On-line data plots were used to determine the number of measurements required to accurately resolve the flows occurring within the individual blade passages. In general, the higher the unsteadiness in the flow, the greater the number of measurements required to resolve the flow. On average, more than 40,000 velocity measurements per component were obtained at each combination of measurement location and operating speed.

Figure 7 illustrates the data reduction process for a velocity component measured at a given location within the model. The top plot shows raw, unaveraged velocities sorted into the
1100 bins of a rotor revolution. The first step in the data reduction process is to simply find the average of the velocities occurring within each of the 1100 bins. The resulting ensemble-averaged mean velocity profile across the entire rotor rev is shown in part b of figure 7 . The next step is to compute the standard deviation (rms) with respect to the mean of the velocities occurring within each bin. This standard deviation, which is a measure of the unsteadiness of the velocity component, is referred to as the unsteady velocity. Figure 7(c) shows the resulting unsteady velocity distribution across the revolution. Next, the data of the 22 individual blade passages are phase-lock averaged into one passage. The process of computing these average passage distributions from the data is illustrated in figure $7(\mathrm{~d})$ for the mean velocities, and in 7(e) for the unsteady velocities. This step involves folding the mean and unsteady (rms) velocity data of the 22 individual blade passages into one passage and computing the mean within each bin. Velocity distributions which span the 50 bins of a single passage result from this process. A final step in the data reduction is to compute a circumferentiallyaveraged mean and unsteady velocity from the average passage distributions. The circumferentially-averaged mean velocity is found by determining the mean of the 50 average passage mean velocities, while the circumferentially-averaged unsteady velocity is the mean of the 50 average passage unsteady velocities. Finally, relative Mach numbers were computed from the axial and tangential velocity components using the method outlined in reference 8 .

\section{Results}

\section{Blade Surface Flow Visualization}

Figure 8 shows a photograph taken of some of the forwardswept fan blades after the model was operated at the high speed condition (13831 $\mathrm{rpm}_{\mathrm{c}}$ ). As mentioned above, the seed material builds up on the blades much more readily downstream of the shock than it does upstream. The line traced out along the blade surface between the downstream region where there is significant seed build-up and the upstream region where there is less identifies the location of the shock on the suction surface of the blade. The image provided in figure 8 indicates that the shock curves along the blade suction surface. The shock is close to the leading edge at the inner radii and progressively further away with increasing span. Near 70 percent span, the blade leading edge takes an abrupt turn forward, while the shock takes a turn downstream. As a result, at the tip of the blade the normal shock is located well back in the passage. Based on this photo one might expect that the tip shocks would be contained within the blade passages when operating at this speed. This was the intent of the forward-swept blade design. 

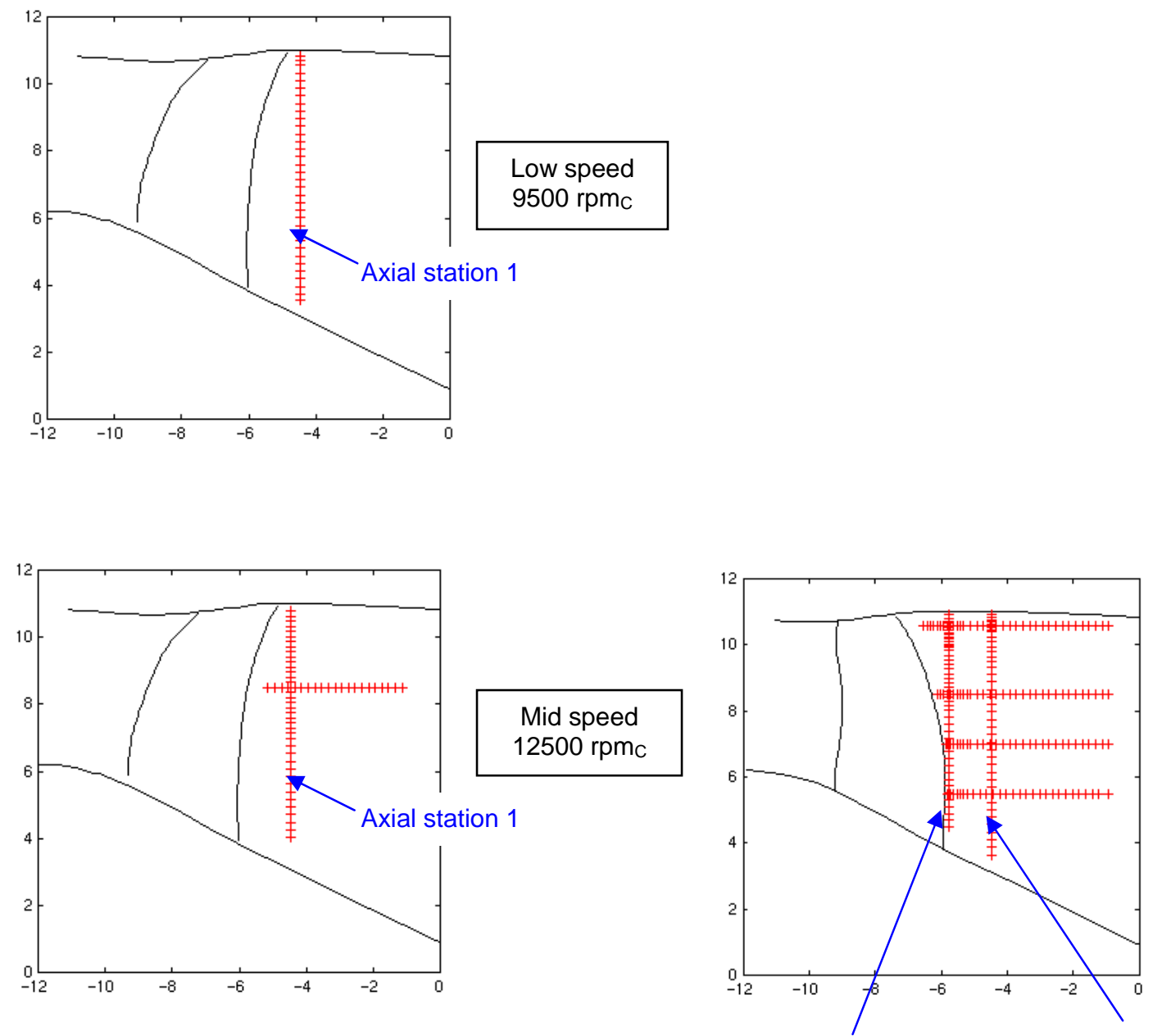

Axial station 2

Axial station 1
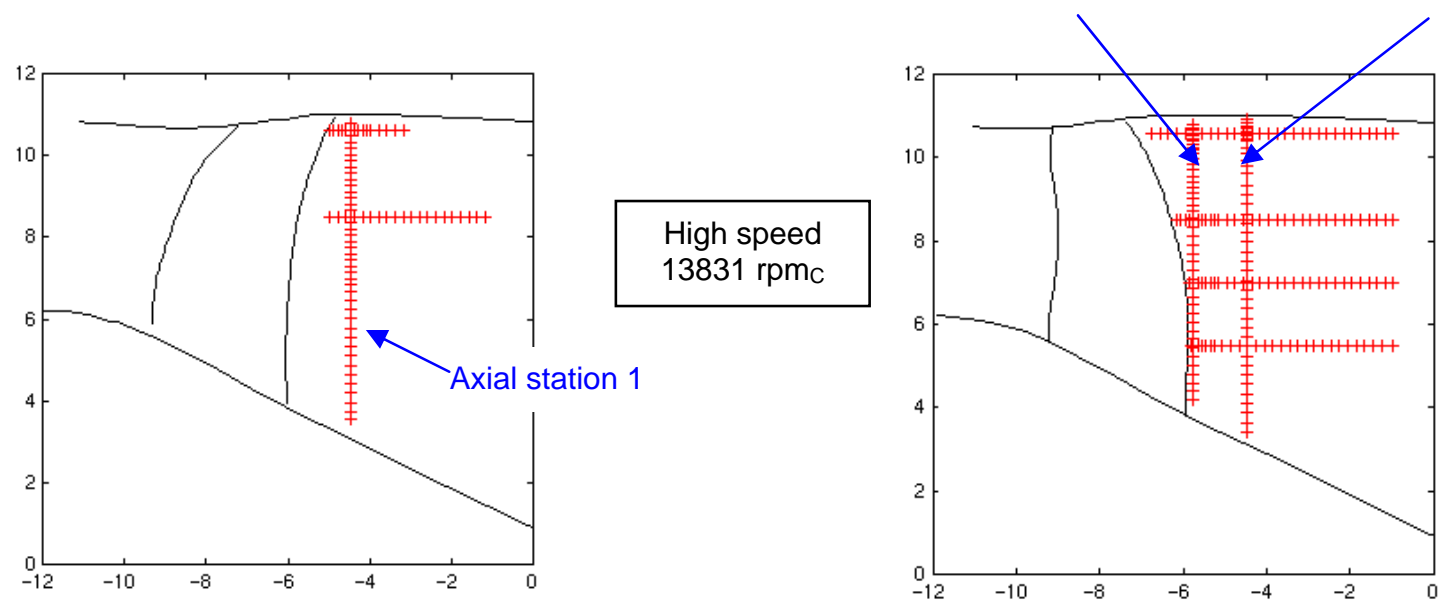

Figure 6.-Schematics showing LDV measurement locations relative to forward-swept fan (left column) and aft-swept fan (right column). 
(a) Raw, unaveraged tangential velocities sorted into 1100 circumferential bins.
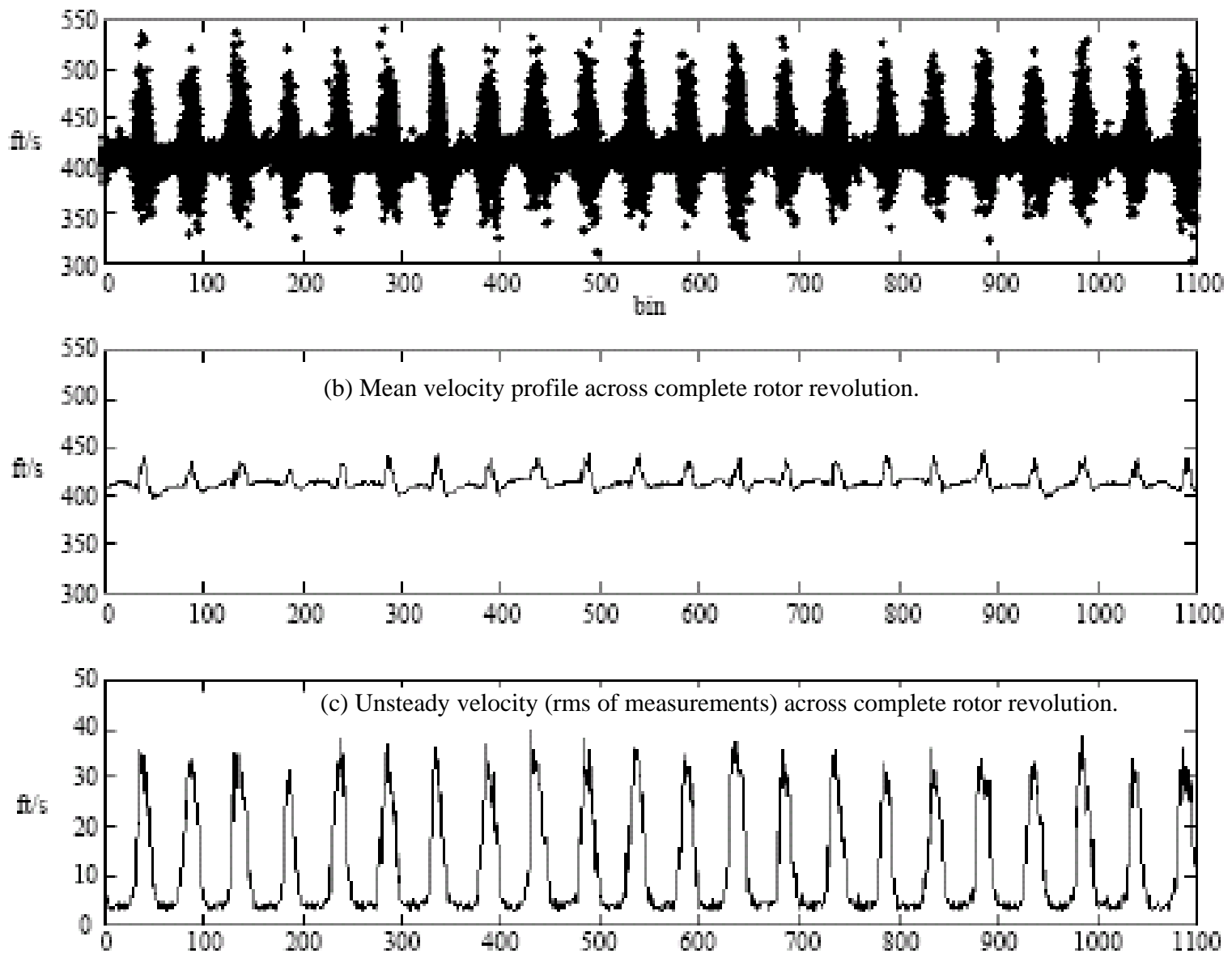

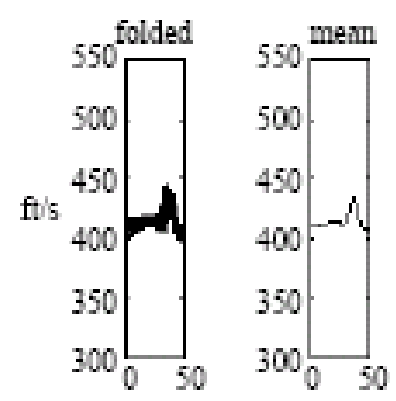

d) "average passage" mean velocities

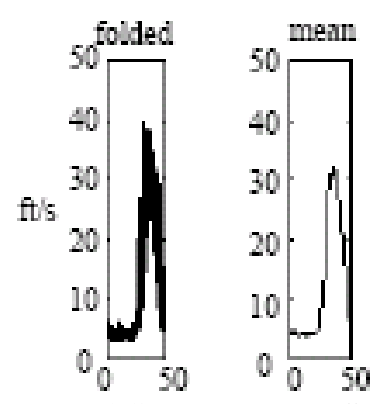

e) "average passage" unsteady velocities

Figure 7.-Illustration of LDV data reduction process. 


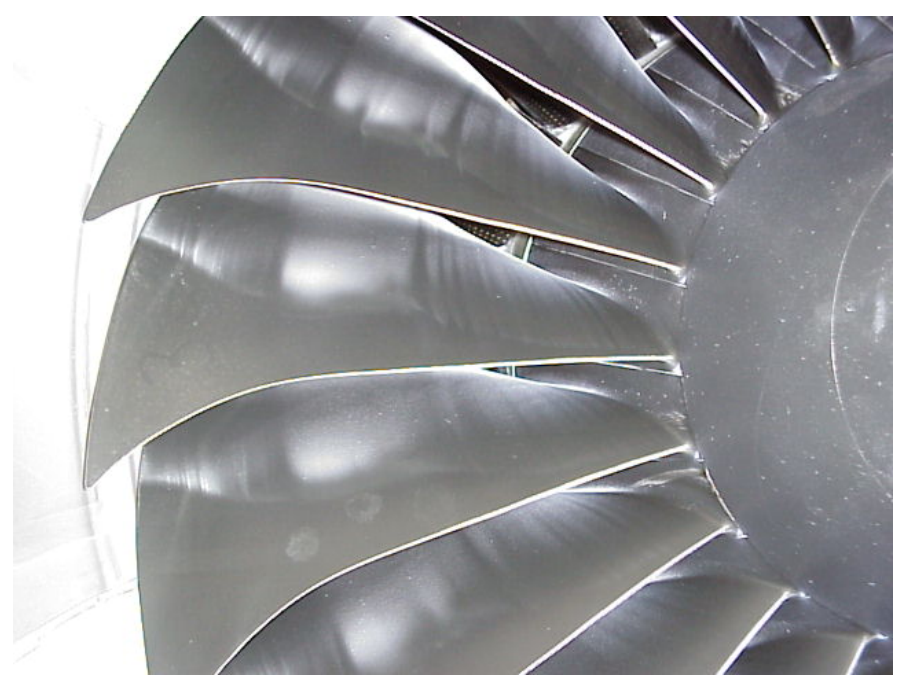

Figure 8.-Photograph of forward-swept fan blades after LDV test in which the rotor was operated at the high-speed condition (13831 rpm $)$ ). The photo shows the build-up of LDV seed particles on the suction side of the rotor blades.

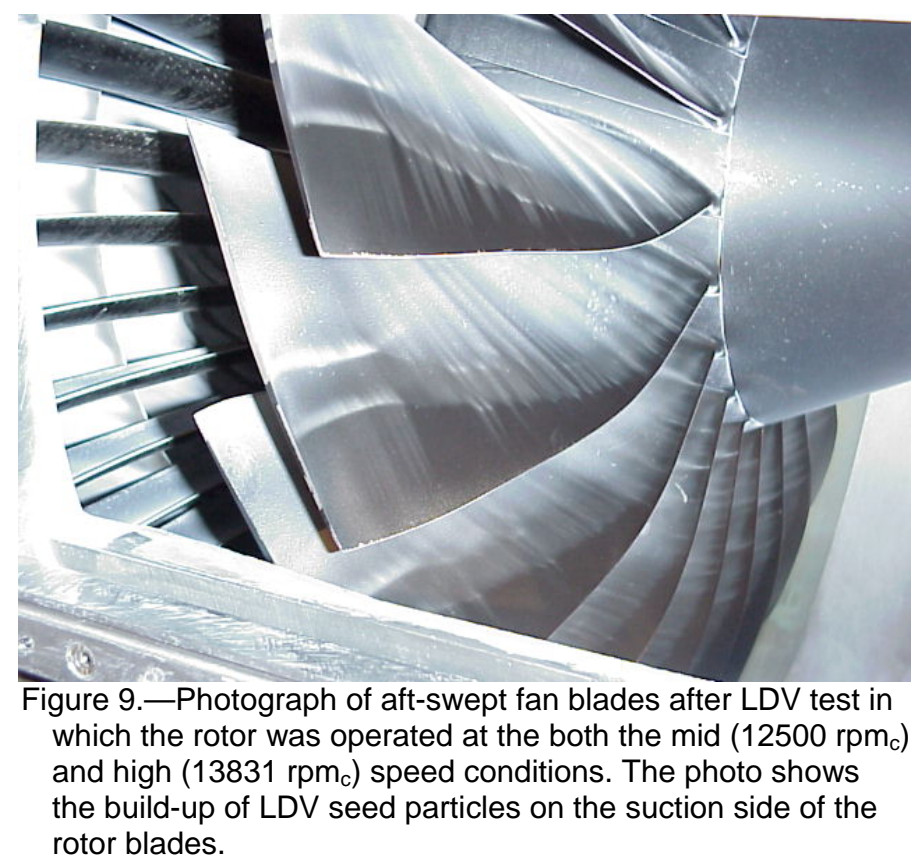

Figure 9 shows a photograph of some of the aft-swept fan blades taken after two LDV test runs-one at mid-speed $\left(12500 \mathrm{rpm}_{\mathrm{c}}\right)$, the other at high-speed $\left(13831 \mathrm{rpm}_{\mathrm{c}}\right)$. The seed pattern on the blades reveals the shock locations corresponding to these two speeds. The shock tends to move downstream along the suction surface as the rotor speed increases. Therefore, the upstream line designates the midspeed condition shock location; the downstream line corresponds to the high-speed shock location. Based on this photo, if a shock was normal to the blade suction surface, it would be reasonable to expect it to extend upstream of the leading edge of the adjacent (clockwise) blade. Shroud unsteady pressure and LDV data provided later will confirm that that the shocks did propagate upstream of the aft-swept rotor at these speeds everywhere along the blade span at which they occurred, including in the tip region. As mentioned above, this difference between the two fans-swallowed tip shocks with the forward-swept fan but propagating shocks with the aft-swept - was expected to lead to less multiple pure tone noise generated by the forward-swept fan. 

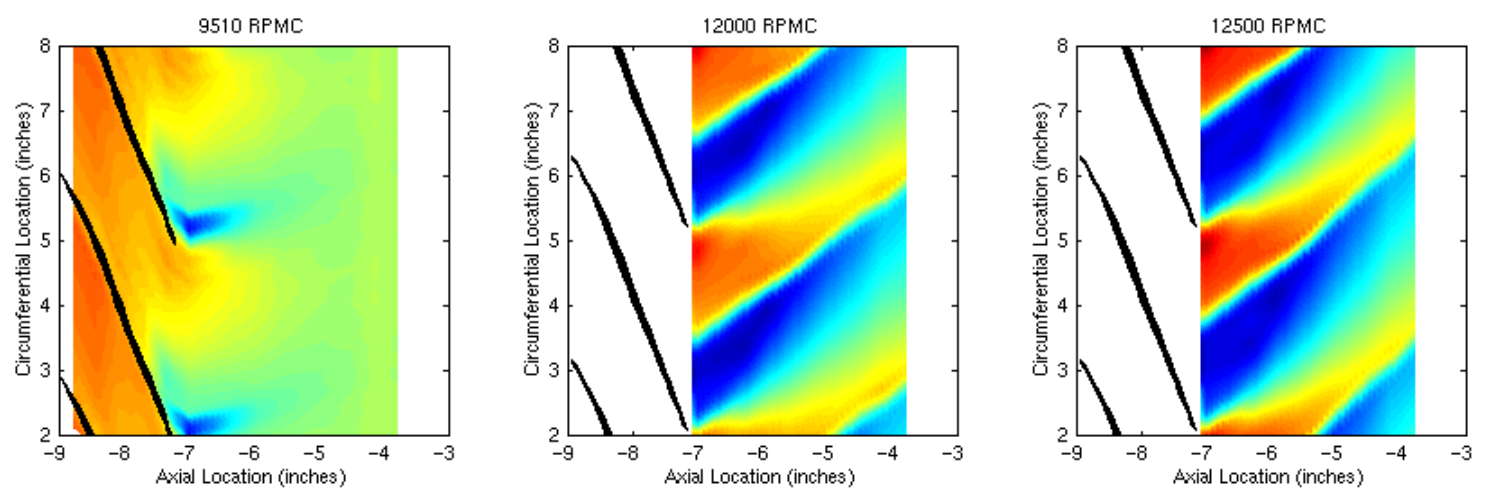

psia
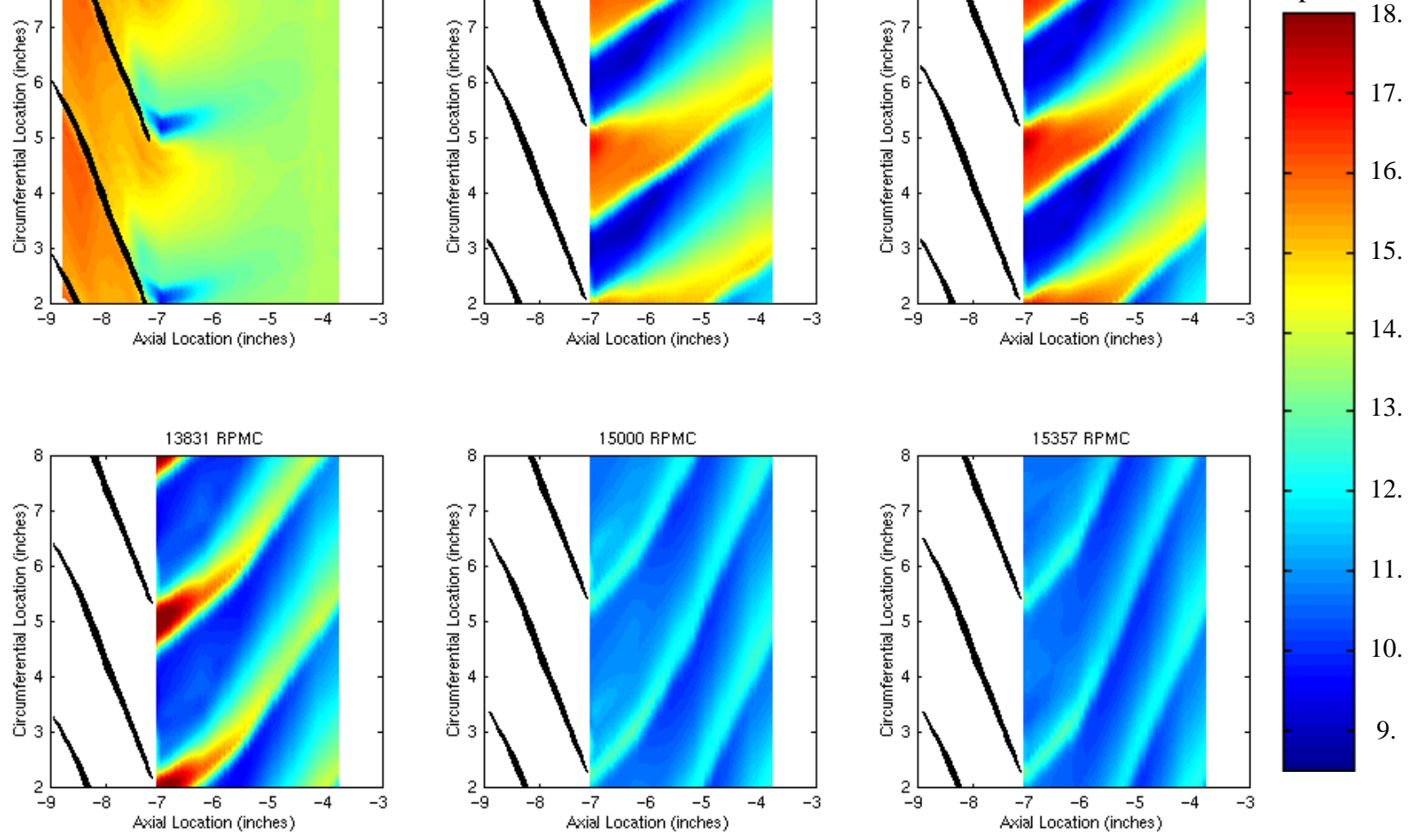

Figure 10.-Unsteady pressure measurements made in the outer duct wall near the tip of the aft-swept fan.

\section{Shroud Unsteady Pressure Measurements}

Figure 10 shows contour plots of static pressure measured on the outer duct wall in the vicinity of the aft-swept rotor blades. Data are presented for six different fan speeds, with each speed listed above the corresponding contour plot. In the outside-looking-in view presented in these plots the flow through the model would be from right-to-left, and the rotor blades (sketched at the left of the contours) would rotate downward. Pressure contours are shown for two of the 18 blade passages. Although pressure measurements were obtained above the tip of the rotor at each speed, intrablade data are only presented at the lowest test speed, $9510 \mathrm{rpm}_{\mathrm{c}}$. The flow within the blade passage was entirely subsonic at this speed, and transonic at the five higher speeds. Intrablade contours are not shown at these higher speeds because the axial spacing between the pressure transducers was too coarse to accurately define the location of the shocks inside the blade passages.

The contours provided in figure 10 show that strong shocks occurred upstream of the tip leading edge of the aft-swept rotor at the three lowest transonic speeds $-12000,12500$, and $13831 \mathrm{rpm}_{\mathrm{c}}$. As suggested by the flow visualization data, these pressure data indicate that a shock which forms at these speeds intersects the suction surface of one blade and spills out ahead of the leading edge of the adjacent (clockwise) blade. This second blade will be referred to in the following discussion as the "adjacent" blade. As the rotor speed is increased from 12000 to $13831 \mathrm{rpm}_{\mathrm{c}}$, the shock moves downstream and approaches the leading edge of the adjacent blade. As it does, both the strength of the shock just upstream of the adjacent blade's leading edge and the amount of curvature in the shock tend to increase. At some speed between 13831 and $15000 \mathrm{rpm}_{\mathrm{c}}$ the strong detached shock gets swallowed inside the blade passage and only a weak, oblique pressure disturbance propagates upstream of the tip of the rotor. This transition results in a significant decrease in the amplitude of the pressure disturbance just upstream the tip leading edge. Tests conducted at Honeywell of a full-scale version of this aft-swept fan using a TFE731-60 engine showed that MPT noise cuts off as rotor speed is increased from the take-off $\left(13831 \mathrm{rpm}_{\mathrm{c}}\right)$ to the design cruise condition $\left(15357 \mathrm{rpm}_{\mathrm{c}}\right)$ (ref. 4).

Figure 11 shows unsteady pressure measurements obtained at the same six rotor speeds, but for the forward-swept fan. There are some notable differences between these contours and the aft-swept fan pressure contours shown in figure 10 . The aft-swept fan contours showed a shock getting stronger and progressively closer to the tip leading edge of the adjacent blade as rotor speed was increased between 12000 and $13831 \mathrm{rpm}_{\mathrm{c}}$. The figure 11 contours do not show either of these characteristics. Instead, the forward-swept fan contours show the strongest pressure disturbance upstream of the fan at the lowest transonic speed, $12000 \mathrm{rpm}_{\mathrm{c}}$. This disturbance 

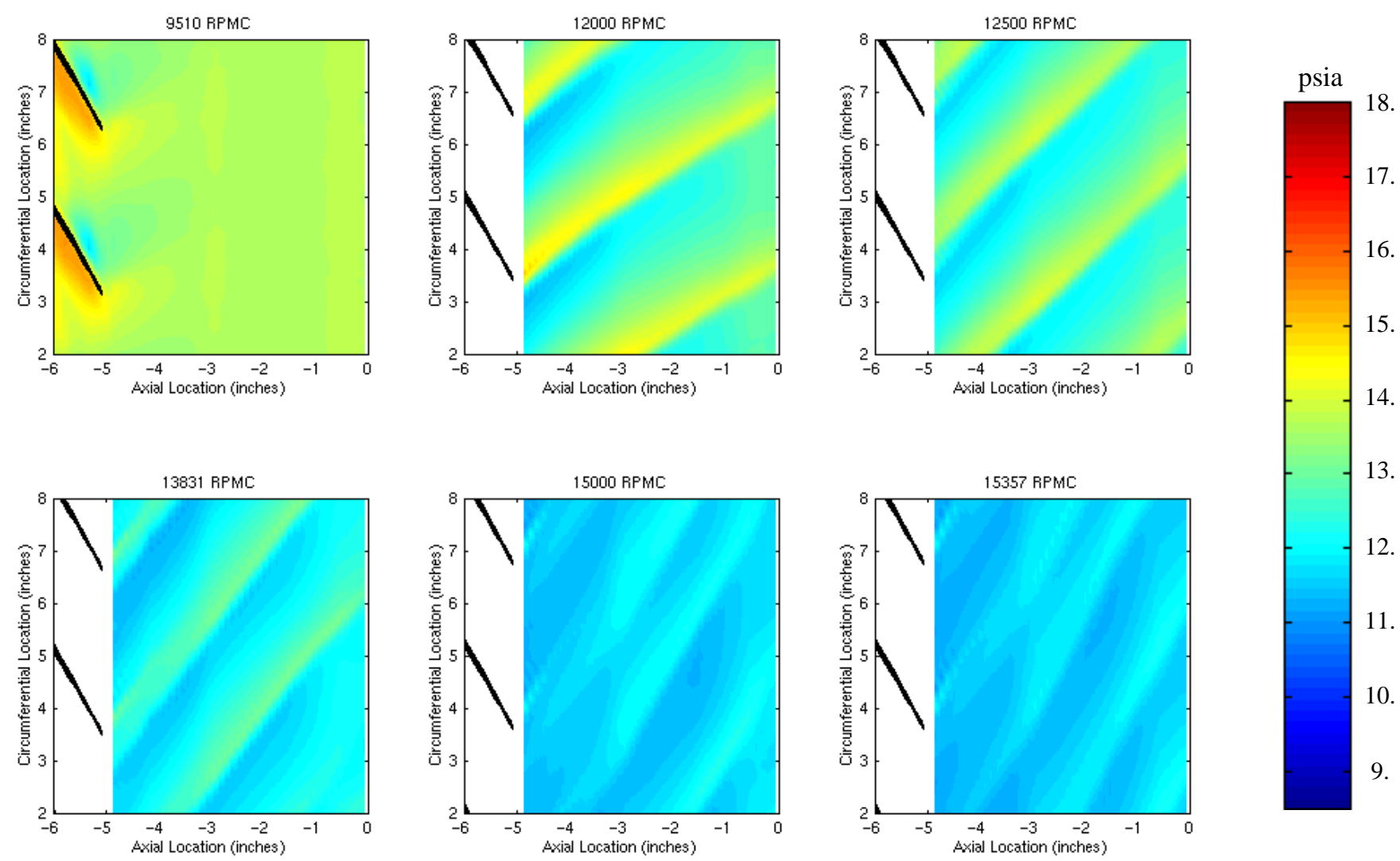

\section{8.

Figure 11.-Unsteady pressure measurements made in the outer duct wall near the tip of the forward-swept fan.

weakens as rotor speed is increased above this speed. At any of the five transonic speeds, the pressure disturbance just upstream of the tip of the forward-swept fan is much weaker than that associated with the aft-swept fan.

Both figures 10 and 11 show blade tip airfoil sections plotted relative to the data. It should be pointed out that there was a good deal of uncertainty associated with the placement of these airfoil sections. The hot (running) shape of the rotors was not known, so there was no way of determining exactly where the blades were relative to the pressure transducers. Given this limitation, the airfoil sections were located based simply on where they seemed to fit within the color contours. Of the two different sets of data, it was easier to locate the airfoil sections relative to the aft-swept fan data because of the stronger pressure disturbances just upstream of that fan. Nevertheless, the coarse axial spacing between transducers made it difficult to determine exactly where the airfoil sections should be located. Consequently, the reader should be aware that the relative locations between the airfoil sections and the contours may not be entirely accurate.

Figure 12 shows this unsteady pressure data plotted in a different form. Here, the amplitude of the pressure disturbances corresponding to the five transonic test speeds are plotted vs. distance upstream of the static position of the tip leading edge for each of the two fans. These distributions illustrate that the decay rate of the pressure disturbance upstream of the fan is a function of the initial amplitude measured just upstream of the leading edge. That is, the higher the initial amplitude, the higher the decay rate. These distributions also illustrate many of the observations made above regarding the contour plots shown in figures 10 and 11 . For one, they clearly show that there is a significant reduction in the amplitude of the disturbance just upstream of the leading edge of the aft-swept fan when the rotor speed is increased between 13831 and $15000 \mathrm{rpm}_{\mathrm{c}}$. The contour plots shown earlier suggest that this reduction occurs when the shock gets swallowed inside the blade passage, leaving only a weak pressure disturbance to propagate upstream of the rotor. Obviously, from an acoustics standpoint, lower amplitude pressure disturbances are beneficial in that they create less noise. As such, it might appear that swallowing the shocks would be preferred to having them propagate upstream. The data of figure 12 also show that at any given speed the amplitude of the pressure disturbance upstream of the tip of the forward-swept fan is lower than that upstream of the aftswept fan. This might suggest that the forward-swept design would produce less noise than the aft-swept.

The problem with these speculations regarding the apparent acoustic benefits of swallowed versus propagating shocks and forward-swept vs. aft-swept rotors is that they are based on limited data. These shroud pressure data only provide a small glimpse of the entire flow field. In turn, that small part of the 


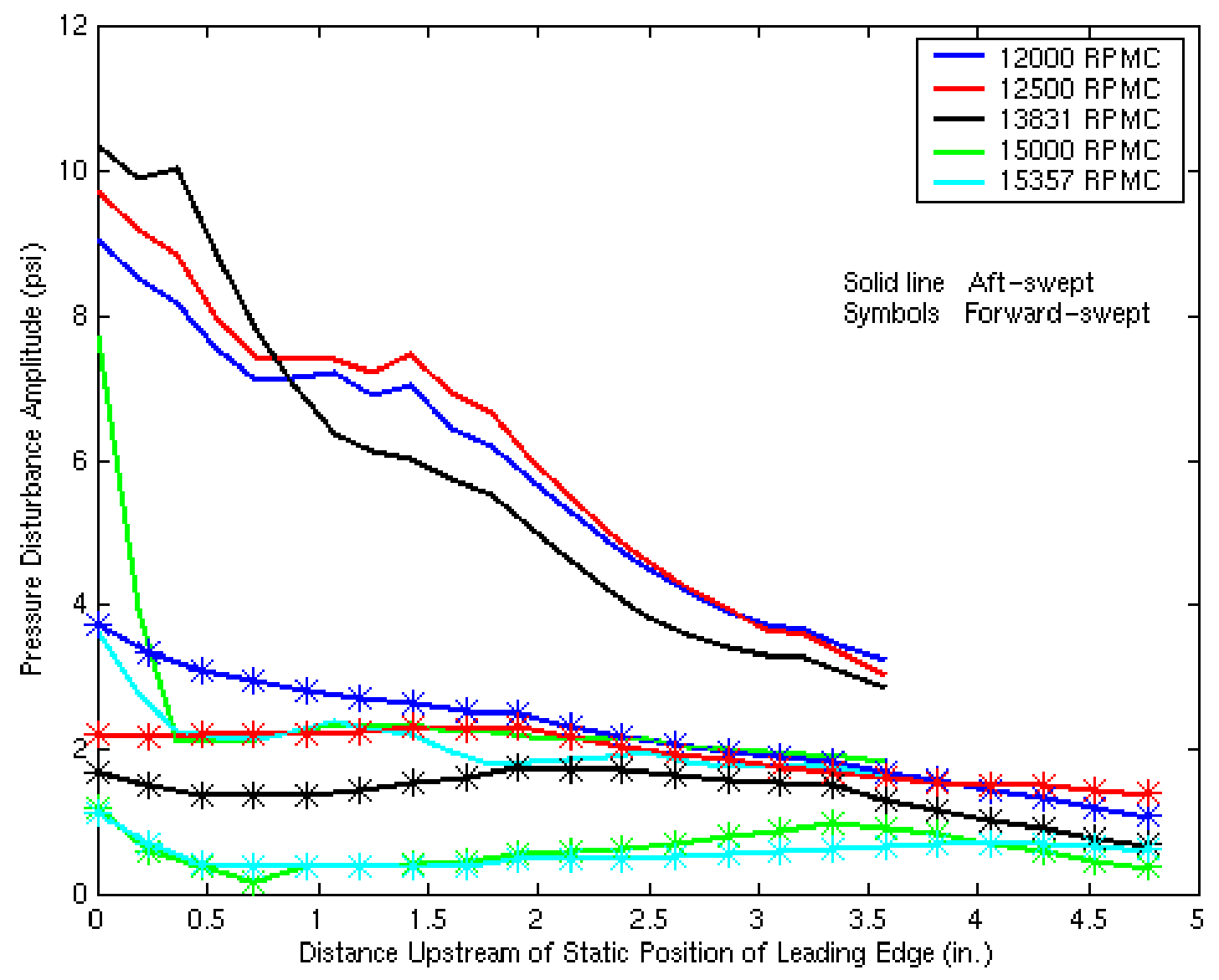

Figure 12.-Variation of the amplitude of the mean pressure disturbance with distance upstream of the tip leading edge for each fan at each of the five tested transonic tip speeds.

flow field has only a minor impact on the total amount of noise produced in the far field. It is also important to realize that changes in the flow in this region which are thought to be beneficial from an acoustics standpoint might lead to changes in the flow in other parts of the flow field which would tend to increase noise. For example, while an increase in the speed of the aft-swept fan from 13831 to $15000 \mathrm{rpm}_{\mathrm{c}}$ might lead to a reduction in the amplitude of the pressure disturbance upstream of the tip of the fan, it might also lead to increases in amplitude further inboard due to stronger shocks generated in that region. In order to understand the impact of the changing flow field on the far field noise it is necessary to have information regarding the changes occurring everywhere in the flow field, not just at the tip of the blade. The LDV data discussed next will help to provide this information.

\section{LDV Measurements}

Figure 13 shows contour plots of ensemble-averaged relative Mach number computed from LDV data obtained during constant axial plane surveys conducted upstream of the forward-swept and aft-swept fans. The view depicted in these contour plots is from downstream of the measurement plane, looking upstream, with the fan rotating clockwise. The sector shown in each plot corresponds to an area equivalent to two blade passages. The top row shows relative Mach number contours measured upstream of the forward-swept fan; the middle and bottom rows show contours measured upstream of the aft-swept fan. The data shown in the top and bottom rows were measured at the same axial plane within the model, at what will be referred to as axial station 1 . The data shown in the middle row were measured further downstream at axial station 2. The contour plots are sorted into different columns according to rotor speed. The first, second, and third columns show data obtained at the low, mid, and high speeds, respectively. The plots provided in the rightmost column depict the axial location at which the data within each row were acquired relative to the model hardware.

The relative Mach number contours provided in the first row of figure 13 show that the flow upstream of the forwardswept fan is much more uniform when it is operating at subsonic (column 1) as opposed to transonic speeds (columns 2 and 3). At subsonic tip speed (column 1), the flow exhibits a smooth, sinusoidal-like variation in the circumferential direction. At the two transonic tip speeds a sawtooth-like variation in the flow is illustrated. The steep gradients in the 

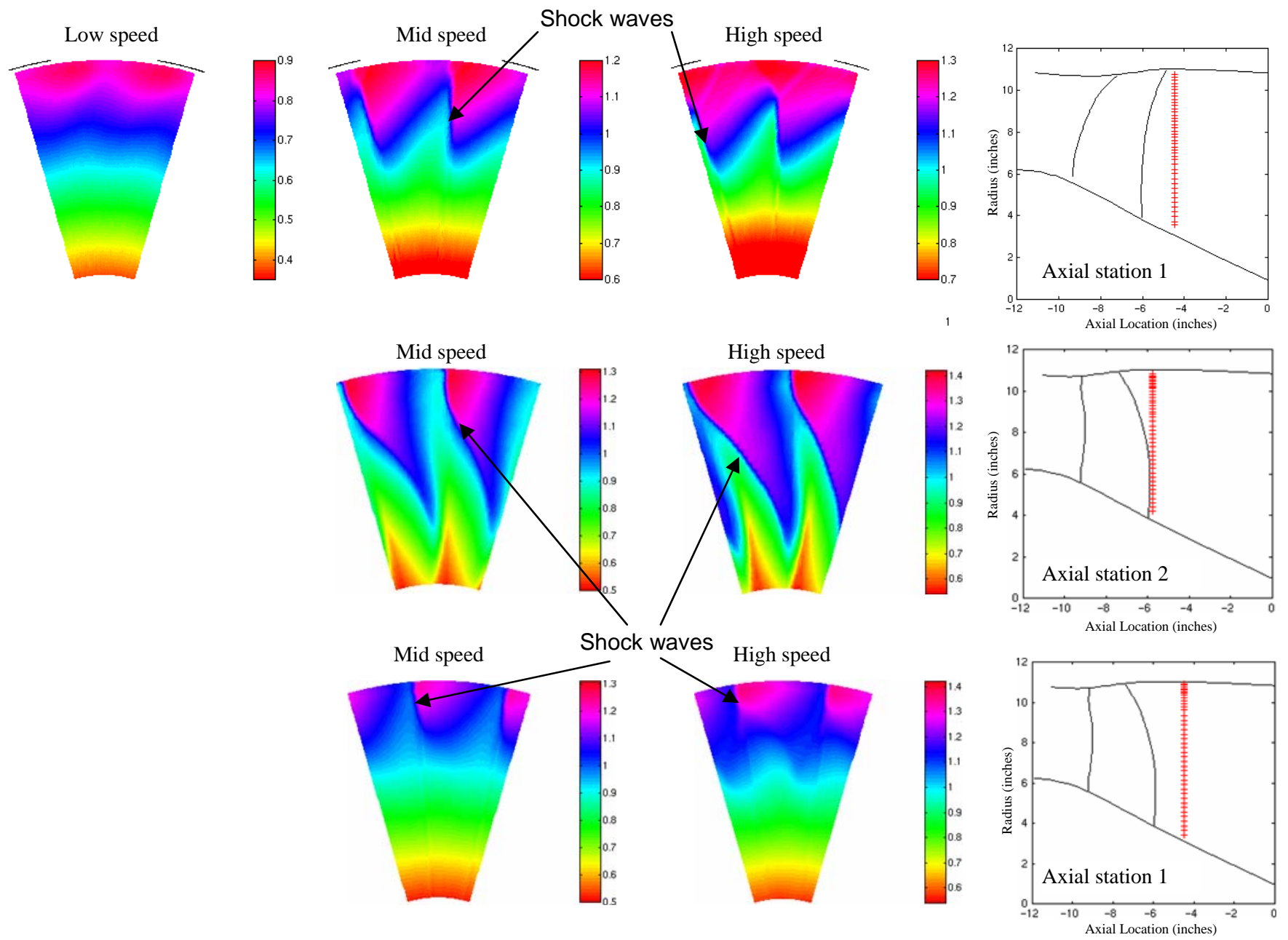

Figure 13.-Ensemble-averaged relative Mach number contours computed from LDV data obtained during constant axial plane surveys conducted upstream of the forward-swept and aft-swept fans. The left, middle, and right columns of contour plots correspond to the low, mid, and high speed conditions, respectively. The schematic at the right shows the axial location at which the data in that row were measured. The view is from downstream looking upstream, with the fan rotating clockwise.

flow associated with this sawtooth pattern result from the shocks on the blades propagating upstream to this measurement plane. Note that the sawtooth pattern does not extend all the way out to the outer case. At the mid speed condition it ends just inside the tip radius while at the high speed condition it ends about 10 percent of the blade span inboard of the tip. The lack of a sawtooth pattern in these regions suggests that the shocks are swallowed inside the blade passages at these radial locations. As mentioned earlier, an important design objective of the forward-swept fan was to swallow the shocks occurring in the tip region when the fan was operating at the takeoff speed (the high speed condition, $13831 \mathrm{rpm}_{\mathrm{c}}$ ). These contour plots indicate that this design objective was met.
In contrast to the forward-swept fan, the contours provided in rows 2 and 3 of figure 13 for the aft-swept rotor show steep gradients in the flow extending all the way to the outer case. This indicates that the shocks generated in the tip region of the aft-swept fan were not swallowed inside the blade passages when operating at either of these two speeds. This result agrees with earlier observations based on the flow visualization and unsteady pressure data.

Figure 14 shows this relative Mach number data in a different form. Each line plot depicted in the rightmost column illustrates how the amplitude of the relative Mach number disturbance measured upstream of the corresponding rotor at a given speed and axial location varies with radius. The red, black, and blue distributions provided in the plot in the upper- 

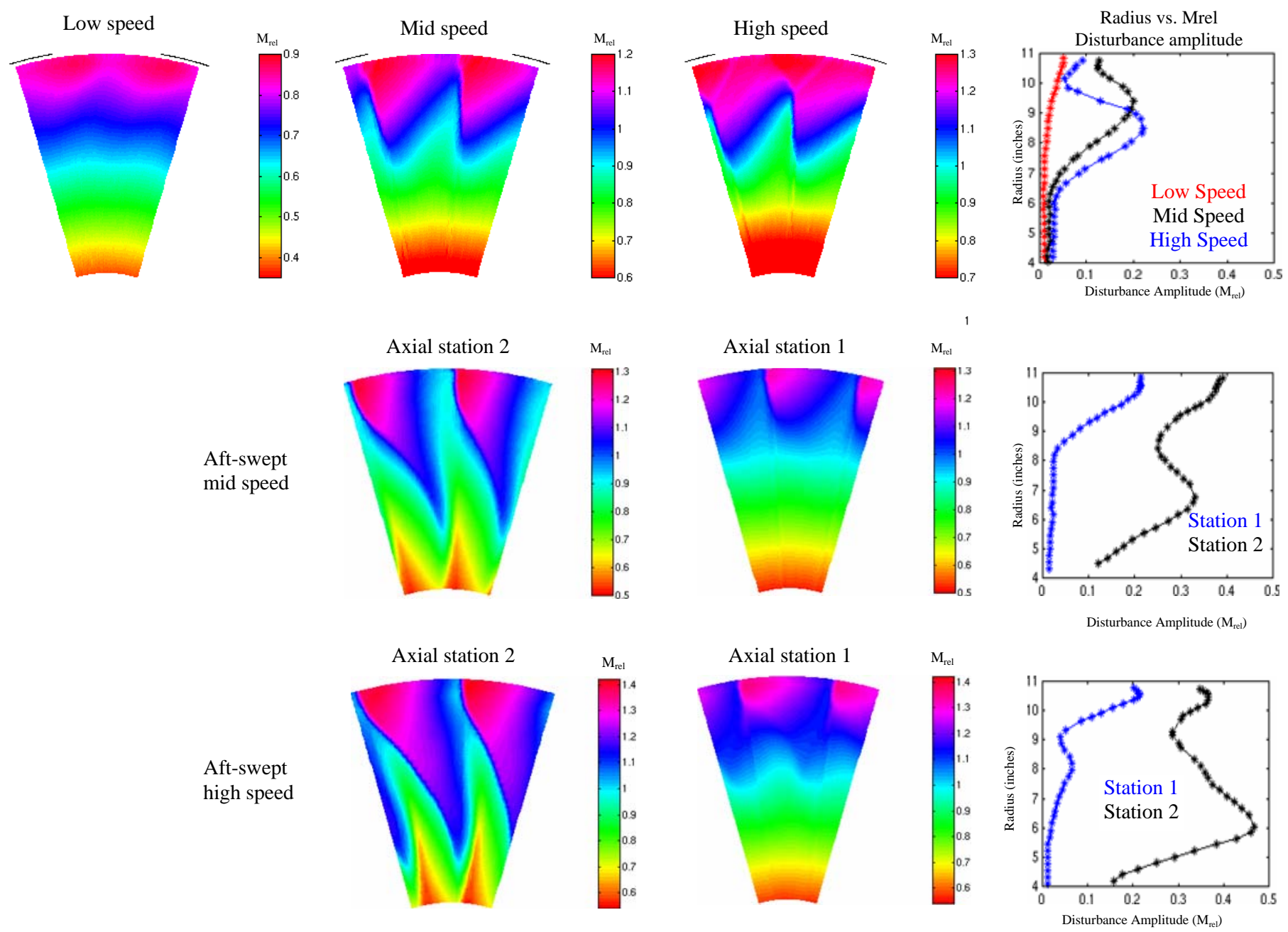

Figure 14.-Ensemble-averaged relative Mach number contours computed from LDV data obtained during constant axial plane surveys conducted upstream of the forward-swept (row 1) and aft-swept fans (rows 2 and 3). The forward-swept data shown in the top row were acquired at axial station 1 at 3 different speeds. The aft-swept data shown in row 2 were acquired at axial stations 1 and 2 with the fan at the mid-speed condition, $12500 \mathrm{rpm}_{\mathrm{c}}$. The aft-swept data shown in row 3 were acquired at axial stations 1 and 2 with the fan at the high-speed condition, $13831 \mathrm{rpm}_{\mathrm{c}}$. The line plots in the rightmost column show how the amplitude of the relative Mach number disturbance varies with radius. The view is from downstream looking upstream, with the fan rotating clockwise.

right hand corner correspond to the low, mid, and high speed data, respectively, measured upstream of the forward-swept fan at axial station 1 . At the low-speed, subsonic condition (red), the amplitude of the disturbance increases slightly with radius. At the mid-speed condition (black) the amplitude of the disturbance in the upstream flow is small inboard of $r=$ 6 in. $(15 \mathrm{~cm})$; increases almost linearly with radius between $r=7$ in. $(18 \mathrm{~cm})$ and $r=9$ in. $(23 \mathrm{~cm})$; and then dips down to lower values in the tip region. In that part of the flow in which the amplitude increases linearly with radius (between $r=7 \mathrm{in}$. $(15 \mathrm{~cm})$ and $r=9$ in. $(23 \mathrm{~cm}))$, the shocks are thought to propagate directly out away from the suction side of the blades such that their path is not altered (either bent or swallowed) by the adjacent blades. Further outboard, at $r=9$ in. $(23 \mathrm{~cm})$, the shocks are thought to begin to bend back around the adjacent blades. They continue to get more bent with increasing radius, until just inboard of the tip they get swallowed inside the blade passage. This interaction (either bending or swallowing) of the shocks with the adjacent blades results in a lower amplitude disturbance upstream of the blade tips.

At the high-speed condition (blue), the trend with radius is similar to that at the mid-speed condition (black), but the midspan region in which the disturbance increases linearly with radius does not extend as far outboard. This indicates that the shocks begin to interact with the leading edge of the adjacent blades at a lower radius when the fan is operated at the high 
speed condition. Relative to the mid-speed condition, the lowamplitude tip region extends over a larger spanwise extent of the blade at the higher speed. This is likely due to the shock being pushed further back in the blade passage as the rotor speed is increased. When the shock is pushed downstream, it gets swallowed over a larger spanwise extent of the blade, resulting in a lower amplitude disturbance upstream of the rotor tip. It is thought that if the shocks in the tip region did not get altered by the adjacent blades (that is, if they were free to propagate out of the blade row without being bent or swallowed) then the almost linear relationship between the disturbance amplitude and radius shown in the mid-span region would continue to hold out to the outer case. This would result in a very high amplitude disturbance upstream of the blade tips, especially at the high-speed condition. The forward sweep of the blades prevents the shocks in the tip region from propagating freely out into the upstream flow. This effectively reduces the amplitude of the flow disturbance just upstream of the blade tips relative to what it would be if the shocks were not altered by the adjacent blades.

The second and third rows of figure 14 correspond to data measured upstream of the aft-swept fan at the mid and highspeed conditions, respectively. Note that the arrangement of the aft-swept fan data on this figure is different than that of figure 13. In figure 13, the data were sorted into columns of constant rotor speed. In figure 14 the aft-swept fan data are sorted into rows of constant rotor speed. This was done so that the line plots presented for the aft-swept data (rows 2 and 3) in the rightmost column of figure 14 could be used to determine how the disturbance amplitude decays with increasing distance upstream of the rotor. The black distributions provided on these plots represent the amplitude of the disturbance measured at axial station 2, just upstream of the aft-swept fan, while the blue distributions represent the amplitude measured 1.27 in. $(3.23 \mathrm{~cm})$ further upstream at axial station 1. The black distributions corresponding to both the mid and highspeed conditions show a very strong disturbance just upstream of the blades everywhere along the blade span at both operating conditions. The blue distributions indicate, however, that this disturbance decays significantly by the time it reaches axial station 1, especially at the inner radii for the lower, midspeed condition, where it decays to almost zero amplitude. This suggests that the large humps seen inboard in the black distributions are not due shock waves; if they were, they would also be seen in the upstream data at station 1. Instead, the disturbances associated with these humps are caused by the potential field of the blades; they result from the rapid changes in velocity which occur when the flow adjusts in order to make its way around the leading edge of a fan blade. At these inner radial locations, the measurement plane (axial station 2) was just a short distance ahead of the upstream-most point on the leading edge of the blades. Consequently, it would be reasonable to expect a very strong influence of the blades on the flow. Unlike in this inner region where the disturbance decays quickly toward zero, the disturbance in the outer region is more persistent. This more persistent disturbance is created by strong shock waves propagating upstream of the tip of the aft-swept rotor.

It is interesting to compare the aft-swept fan relative Mach number disturbance amplitude plots measured at mid-speed with those measured at high-speed. These plots are provided at the right in figure 15. Spanwise distributions of the amplitude of the disturbance measured at both axial stations 1 and 2 are shown for both rotor speeds. Inboard of where strong shocks exist on the blades, the data behave as expected; that is, the amplitude of the disturbance measured just upstream of the blade at axial station 2 (black) increases with rotor speed. In the outer regions of the flow, however, where strong shocks exist, the trend depicted might not be expected. In this part of the flow, the disturbance measured at mid-speed is actually slightly higher in amplitude than that measured at high-speed. This behavior is thought to be associated with the extent to which the shocks interact with the adjacent blades. As indicated in the unsteady pressure contours presented previously in figure 10, the shocks bend more around the adjacent blades at high speed $\left(13831 \mathrm{rpm}_{\mathrm{c}}\right)$ than at mid-speed $\left(12500 \mathrm{rpm}_{\mathrm{c}}\right)$. The unsteady pressure data shown in figure 10 indicated that the increased bending in the shock was associated with a slight reduction in the amplitude of the pressure disturbance upstream of the very tip of the aft-swept rotor. The LDV data presented here in figure 15 indicate that this reduction in the amplitude of the flow disturbance is not confined to the very tip; it also extends further inboard. All else being equal, one might expect a reduction in the amplitude of the flow disturbance in this region to correlate with reductions in noise. The blue distributions shown in figure 15, however, indicate that all else is not equal. Instead, the reduction in the outer region is accompanied by an increase in the disturbance amplitude further inboard. This, therefore, is an illustration of a point made earlier - that changes in the flow in one region that are thought to be beneficial from an acoustics standpoint are often accompanied by changes in another part of the flow which could be expected to increase noise. In this case the two effects appear to offset, so it would seem likely that the overall amount of noise associated with this part of the flow field would not change a great deal as the speed of the aft-swept fan is increased from the mid to the high speed.

It is also interesting to compare the aft-swept fan relative Mach number disturbance amplitude data with that measured upstream of the forward-swept fan. Figure 16 shows spanwise distributions of the amplitude of the disturbance measured upstream of the two rotors at axial station 1 while they were operating at the high speed condition. As illustrated, very significant differences in the flow disturbance amplitude were measured upstream of the two fans at axial station 1. In the tip region the aft-swept fan generates the larger disturbance, whereas in the midspan region the opposite is true, the 

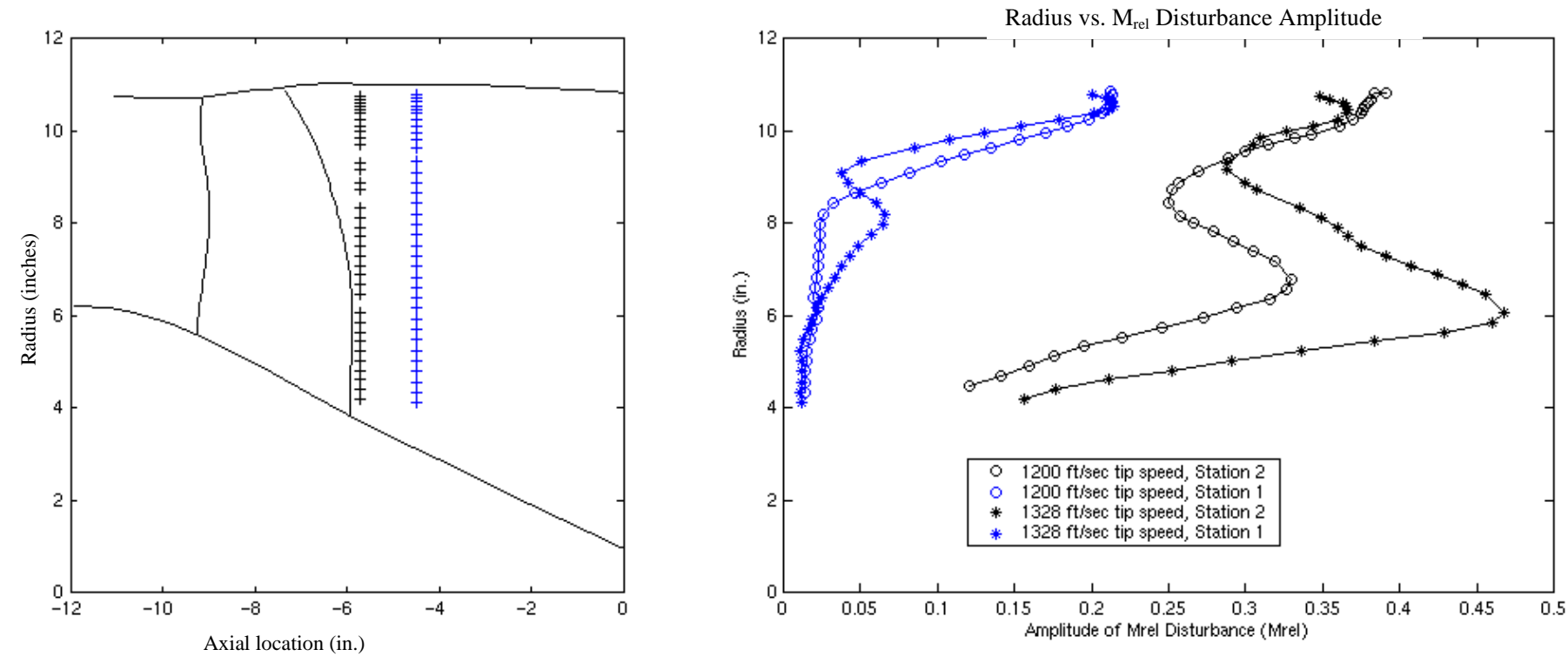

Figure 15.- Spanwise distributions of the amplitude of the relative Mach number disturbance measured upstream of the aft-swept fan at both axial station 1 (blue) and 2 (black) at the mid (open circles) and high (asterisks) speed conditions.
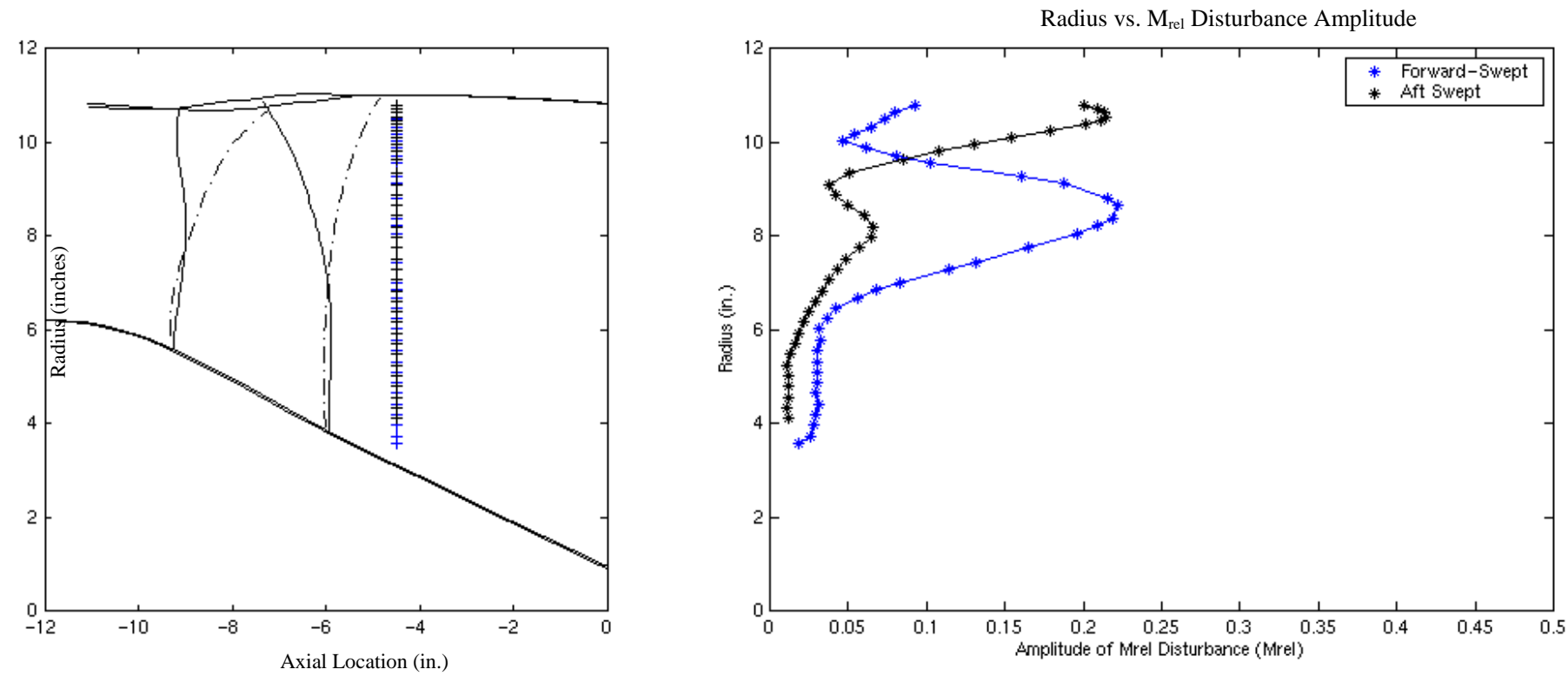

Figure 16.-Comparison of spanwise distributions of the relative Mach number disturbance amplitude measured upstream of the aft-swept (black) and forward-swept (blue) fans while operating at the high speed condition.

forward-swept fan generates the larger disturbance. The amplitude of the disturbance measured upstream of the tip of the aft-swept rotor was at least twice as large as that measured upstream of the forward-swept. This difference is due to the differences in the shocks occurring in the tip region-with the forward-swept fan the shocks were swallowed, whereas with the aft-swept fan they were not. Unlike the tip region, in the midspan region the shocks spill out in front of both rotors. Therefore, the higher amplitude disturbance measured in the midspan region upstream of the forward-swept fan can not be explained using a similar argument based on swallowed vs. propagating shocks. At this operating speed, the axial Mach number is roughly 0.54 , so shocks should appear on the blades at roughly $7.8 \mathrm{in} .(19.7 \mathrm{~cm})$ radius.

Figure 17 provides some insight as to why a stronger disturbance was measured in the midspan region upstream of the forward-swept fan. This figure shows contour plots measured at the high speed condition via constant radial 

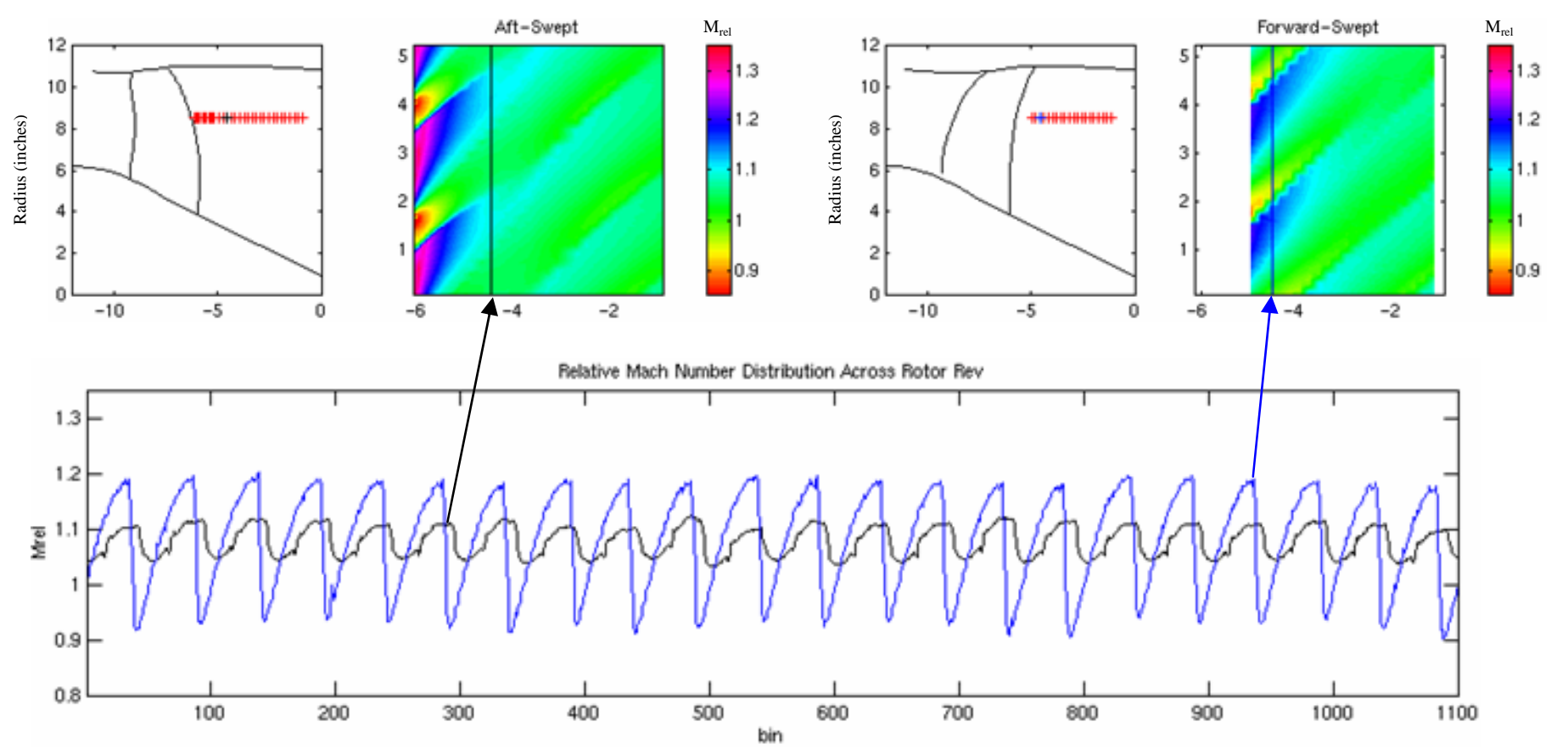

Figure 17.-Comparison of relative Mach numbers measured upstream of the aft-swept and forward-swept fans during constant radial traverses at $r=8.5 \mathrm{in}$. The contours provided on the upper left plot were measured upstream of the aft-swept fan; those provided on the upper right were measured upstream of the forward-swept fan. The line plot in the middle of the page compares the circumferential distributions of relative Mach obtained by slicing through the above contours at the locations indicated by the arrows.

surveys conducted upstream of both fans at $r=8.5$ in. $(21.6 \mathrm{~cm})$. The contour plot in the upper left shows relative Mach number contours measured upstream of the aft-swept rotor at the measurement locations depicted in the schematic at the left of this plot. Likewise, the contour plot in the upper right shows the same sort of data measured upstream of the forward-swept fan at the locations depicted on the plot directly to its left. Each contour plot shows two blade passages of data. A comparison of these contour plots indicates that the shock waves generated at this radius by the aft-swept rotor were not necessarily any weaker than those generated by the forwardswept fan. Instead, these data suggest that the primary reason that a weaker disturbance was measured upstream of the aftswept fan at axial station 1 has to do with the sweep of the blades. The difference in blade sweep places the leading edge of the aft-swept rotor further downstream of axial station 1 than the leading edge of the forward-swept rotor. This can also be seen in the schematic presented at the left in figure 16 which shows an overlay of the planform shapes of the two different types of blades. Since the aft-swept blades are further downstream, the shocks generated by the blades have more time to decay before they reach axial station 1. Consequently, the aft-swept fan generates a weaker disturbance at axial station 1 than the forward-swept fan.

As shown above, the forward-swept fan swallowed the shocks occurring in the tip region when operating at the takeoff speed, whereas the aft-swept fan did not. This difference was expected to lead to differences in the amount of multiple pure tone noise generated by the two different fans. As mentioned in the introduction, however, the MPT noise generated by the forward-swept fan was not much different than that of the aft-swept fan. At first glance it might appear that the spanwise distributions provided in figure 16 could be used to explain why the MPTs were not reduced with the forward-swept fan. This figure shows two distinctly different regions in the flow field. In the tip region the aft-swept fan generated a larger flow disturbance than the forward-swept, whereas in the midspan region the opposite was true. As such, it might appear that the benefit in the tip region associated with the forward-swept fan might be offset by the mid-span region in such a way that comparable levels of MPT noise would be generated by the two fans. The data provided next, however, indicate that this explanation may not be valid.

Figure 18 shows data measured during constant radial surveys conducted at $r=10.6 \mathrm{in}$. $(26.9 \mathrm{~cm})$ upstream of the forward-swept and aft-swept fans at the high speed condition. The contour plot at the top left shows relative Mach numbers measured upstream of the aft-swept rotor at the locations depicted in the schematic at the left of this plot, while the contour plot at the top right shows similar data measured upstream of the forward-swept fan at the locations depicted in the schematic at its left. These contours show strong shocks propagating upstream of the tip of the aft-swept rotor and a much weaker disturbance upstream of the forward-swept fan. 

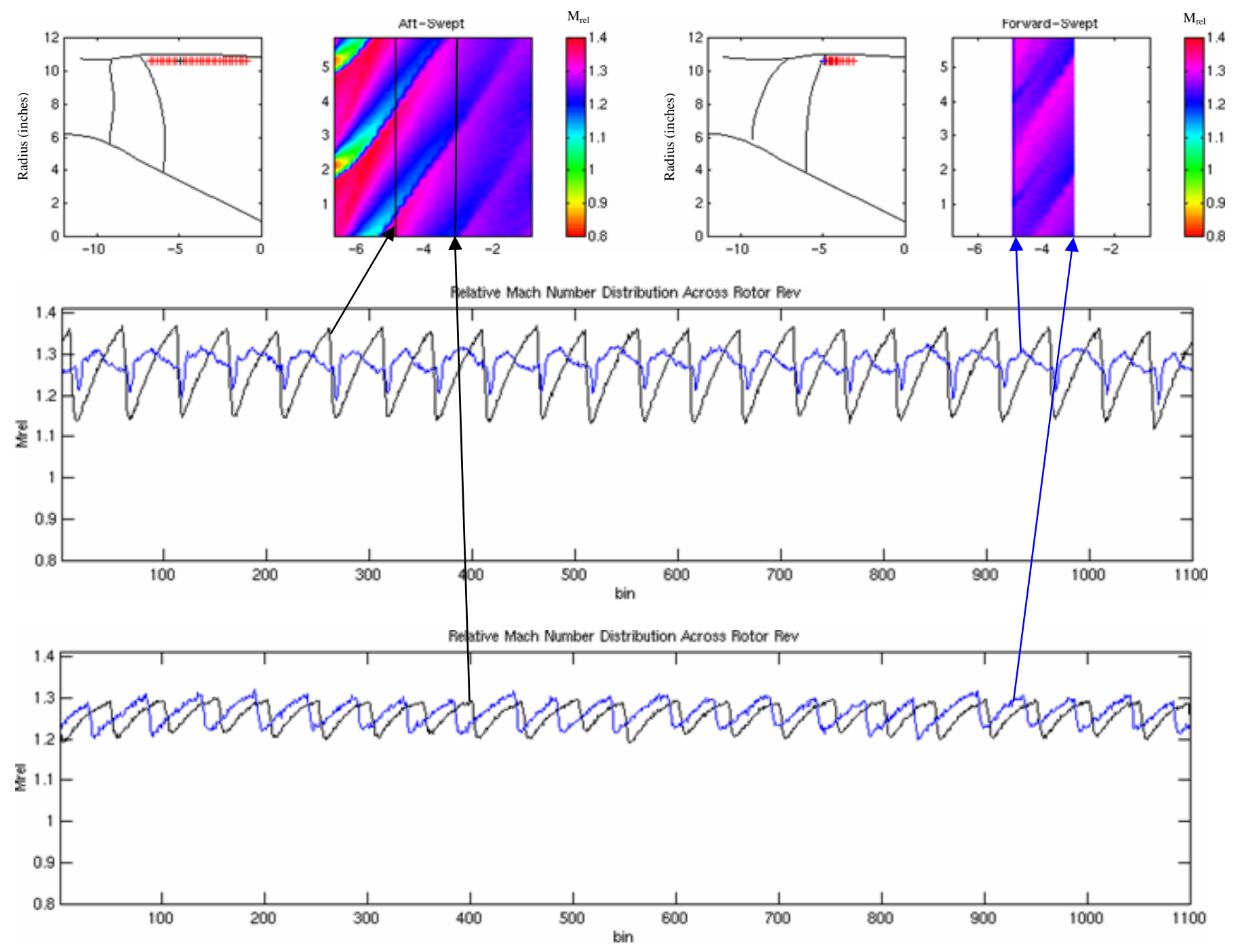

Figure 18.-Comparison of relative Mach numbers measured upstream of the aft-swept and forward-swept fans during constant radial traverses at $r=10.6$ in. The contours provided on the upper left plot were measured upstream of the aft-swept fan; those provided on the upper right were measured upstream of the forward-swept fan. The line plot in the middle of the page compares the circumferential distributions of relative Mach obtained by slicing through the above contours at a downstream location; the line plot at the bottom compares relative Mach numbers measured further upstream.

The plot at the middle of the page shows some of this data in more detail. This plot shows circumferential distributions of relative Mach number obtained by slicing through the above contours at the downstream-most point in the flow at which data were obtained with both fans. Unlike the contour plots, however, which only show two blade passages of data, the line plots show the relative Mach number distributions measured upstream of all 22 blade passages. The axial location corresponding to this slice through the contours is very close to that of axial station 1 . It is not surprising then, that these distributions show the same behavior that was mentioned in the discussion of the axial station 1 data shown in figure 16 . That is, that the aft-swept fan generates a much stronger disturbance at this location than the forward-swept fan. It is interesting, however, to look at what happens to the disturbances as they propagate upstream of this point. The plot at the bottom of the page compares the two flows measured at the upstream-most point in the flow field at which data were obtained with both fans. This comparison indicates that the amplitude of the disturbance measured at this point in the flow field is essentially the same regardless of which rotor was being tested. This is surprising considering that the shocks occurring at this radius were swallowed with one fan but not with the other.

Figure 19 shows data measured further inboard at $r=8.5 \mathrm{in}$. $(21.6 \mathrm{~cm})$ while both fans were operating at the high speed condition. As shown previously in figure 16, this radius corresponds to the location of the peak disturbance measured 

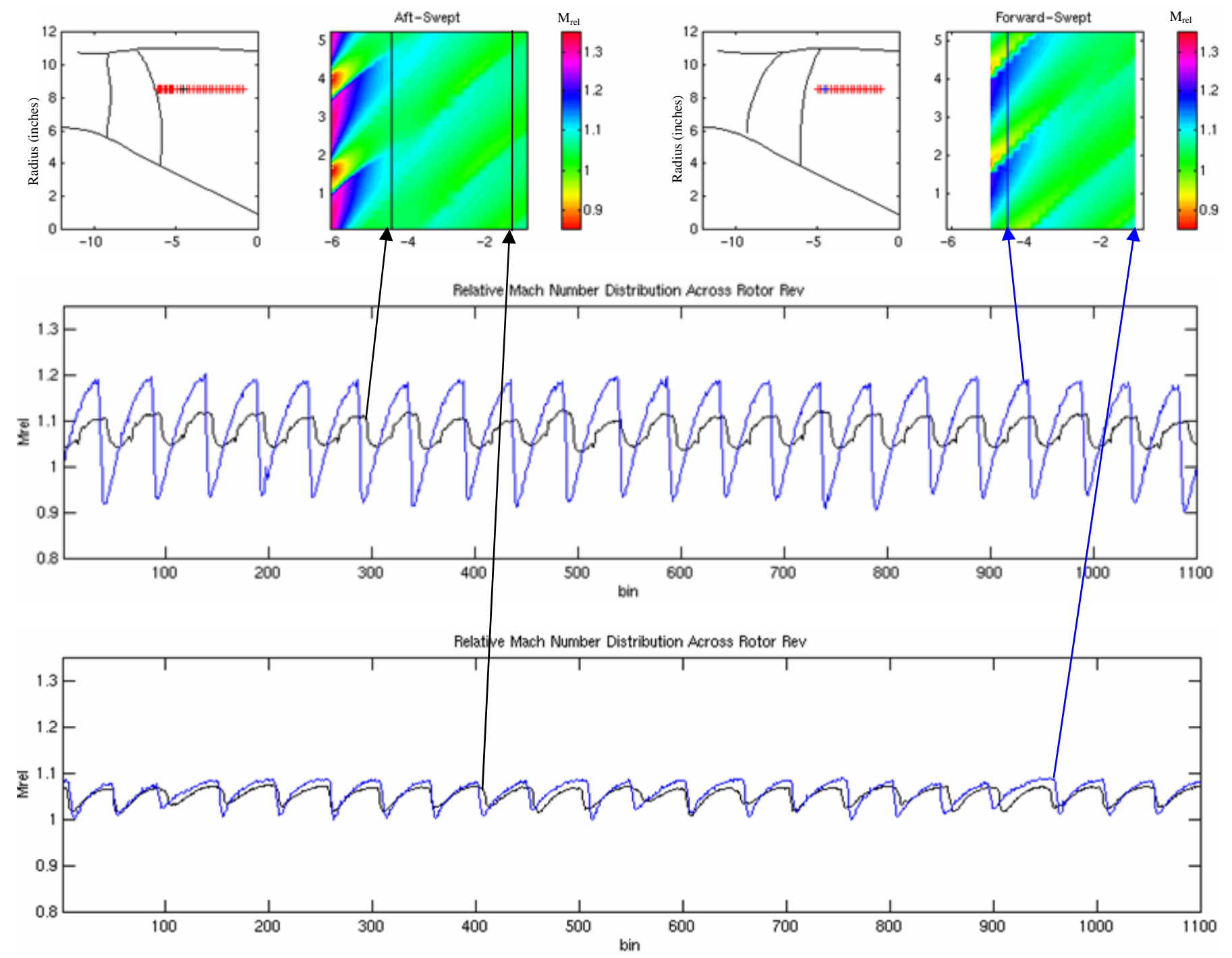

Figure 19.-Comparison of relative Mach numbers measured upstream of the aft-swept and forward-swept fans during constant radial traverses at $r=8.5 \mathrm{in}$. The contours provided on the upper left plot were measured upstream of the aft-swept fan; those provided on the upper right were measured upstream of the forward-swept fan. The line plot in the middle of the page compares the circumferential distributions of relative Mach obtained by slicing through the above contours at a downstream location; the line plot at the bottom compares relative Mach numbers measured further upstream.

upstream of the forward-swept fan at axial station 1. The contour plot in the upper left shows data measured upstream of the aft-swept fan; while that in the upper right corresponds to the forward-swept fan. The line plot shown at the middle of the figure compares circumferential distributions of relative Mach number measured at the downstream-most location in the flow at which data were obtained with both fans. This location is near axial station 1 and, as expected based on the data shown in figure 16, the distributions shown here indicate that the disturbance generated at this location by the forwardswept fan is much larger than that generated by the aft-swept fan. Once again, however, it is interesting to observe what happens to the disturbances as they propagate upstream. The line plot at the bottom of the figure shows the disturbances measured at the upstream-most location in the flow at which data were obtained with both fans. Like the data shown in figure 18 for the outer radial location, the data shown here indicate that the two disturbances have basically the same amplitude further upstream.

The data presented in the previous two figures show that despite very significant differences in the flows generated just upstream of the two rotors, the two flows look much more similar at a distance of about one axial blade chord further upstream. This is important since it suggests that one needs to be careful about drawing conclusions regarding the amount of shock noise to be expected in a certain situation based solely on measurements (or CFD predictions, for that matter) made very close to the rotor. The data provided here suggest that the conclusion drawn regarding the expected shock noise would depend heavily on which part of the flow field is considered. 
In other words, looking at the flow just upstream of the fan could lead to an entirely different conclusion than looking further upstream. In reality, in order to understand the significance of the shock waves on the noise generated in the far field it is necessary track the behavior of the shocks all the way out to the inlet throat. Once they make it to the throat, the pressure disturbances associated with the shock waves can propagate out to the far field.

This observation regarding the necessity to track the shocks throughout the inlet in order to determine their effect on the far field noise is not new. Prasad and Feng (ref. 3) indicated that in order to use CFD predictions to determine the amount of noise generated by shocks on fan blades that it is important to consider how those shocks propagate through the inlet. They showed that differences in the inlet contour can have a very significant effect on the amount of shock noise generated. The data provided herein tend to confirm that it is important to consider how the shock waves evolve in the inlet in order to determine their effect on the far field noise.

\section{Conclusions}

1. The flow visualization data indicate that at the takeoff speed, $13831 \mathrm{rpm}_{\mathrm{c}}$, the passage shocks occurring in the tip region of the forward-swept fan are further back in the blade passage than with the aft-swept fan.

2. The shroud unsteady pressure measurements show that strong detached shocks propagate upstream of the tip of the aft-swept rotor at the three lowest transonic test speeds. At some speed between 13831 and $15000 \mathrm{rpm}_{\mathrm{c}}$ the shocks are swallowed inside the blade passage, leaving only a relatively weak pressure disturbance attached to the tip leading edge of the aft-swept rotor. The pressure disturbance just upstream of the tip of the blades is much weaker when the shocks are swallowed versus when they are propagating.

3. The shroud unsteady pressure measurements made with the forward-swept fan do not show a strong shock propagating upstream of the tip of that fan at any of the tested speeds.
4. At the takeoff speed (13831 $\mathrm{rpm}_{\mathrm{c}}$ ), the LDV data confirm that the passage shocks were swallowed inside the tip region with the forward-swept blades, but not with the aftswept blades. Further inboard, in the midspan region the shocks spill out in front of both rotors.

5. Despite drastic differences in the flows just upstream of the two rotors, the two fan flows look much more alike about one axial blade chord further upstream. As such, the LDV data provided herein suggest that it is unwise to attempt to determine the effect that shocks have on far field noise by focusing only on measurements (or CFD predictions) made very near the rotor. Instead, these data suggest that it is important to track the shocks throughout the inlet.

\section{References}

1. Benzakein, M.J., Kazin, S.B., Savell, C.T., "Multiple Pure Tone Noise Generation and Control,” AIAA paper A731021, 1973.

2. Hayden, R.E., Bliss, D.B., Murray, B.S., Chandiramani, K.L., Smullin, J.I., Schwaar, P.G., "Analysis and Design of a High Speed, Low Noise Aircraft Fan Incorporating Swept Leading Edge Rotor and Stator Blades," NASA CR-135092, 1977.

3. Prasad, D., Feng, J., "Propagation and Decay of Shock Waves in Turbofan Engine Inlets," ASME paper GT2004-53949, 2004.

4. Weir, D.S., "Design and Test of Fan/Nacelle Models, Quiet High Speed Fan,” NASA/CR-2003-212370, 2003.

5. Dittmar, J.H., Elliott, D.M., Fite, E.B., "The Noise of a Forward Swept Fan,” NASA/TM-2003-212208, November 2003.

6. Heidelberg, L.J., "Comparison of Tone Mode Measurements for a Forward Swept and Baseline Rotor Fan,” NASA/TM-2003-212378, June, 2003.

7. Fite, E.B., “Aerodynamic Performance Measurements for a Forward Swept Low Noise Fan,” NASA/TM-2006214413, December, 2006.

8. Strazisar, A.J., Wood, J.R., Hathaway, M.D., Suder, K.L., "Laser Anemometer Measurements in a Transonic AxialFlow Fan Rotor,” NASA TP-2879, November, 1989. 


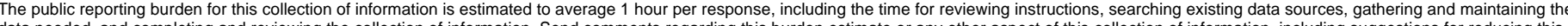
data needed, and completing and reviewing the collection of information. Send comments regarding this burden estimate or any other aspect of this collection of information, including suggestions for reducing this burden, to Department of Defense, Washington Headquarters Services, Directorate for Information Operations and Reports (0704-0188), 1215 Jefferson Davis Highway, Suite 1204, Arlington, VA 22202-4302.

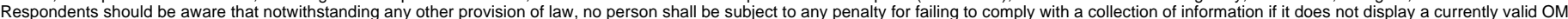
control number.

PLEASE DO NOT RETURN YOUR FORM TO THE ABOVE ADDRESS.

\begin{tabular}{l|l|l}
\hline 1. REPORT DATE (DD-MM-YYYY) & $\begin{array}{l}\text { 2. REPORT TYPE } \\
\text { Technical Memorandum }\end{array}$ & 3. DATES COVERED (FrOm - To) \\
\hline
\end{tabular}

01-11-2007

Technical Memorandum

\title{
4. TITLE AND SUBTITLE
}

Shock Characteristics Measured Upstream of Both a Forward-Swept and an Aft-Swept Fan

\section{5a. CONTRACT NUMBER}

b. GRANT NUMBER

6. AUTHOR(S)

Podboy, Gary, G.; Krupar, Martin, J.; Sutliff, Daniel, L.; Horvath, Csaba

5d. PROJECT NUMBER

5e. TASK NUMBER

5f. WORK UNIT NUMBER

WBS 561581.02.08.03.03.01

7. PERFORMING ORGANIZATION NAME(S) AND ADDRESS(ES)

National Aeronautics and Space Administration

John H. Glenn Research Center at Lewis Field

8. PERFORMING ORGANIZATION REPORT NUMBER

Cleveland, Ohio 44135-3191

E-16112

\section{SPONSORING/MONITORING AGENCY NAME(S) AND ADDRESS(ES)}

National Aeronautics and Space Administration

Washington, DC 20546-0001

\author{
10. SPONSORING/MONITORS \\ ACRONYM(S) \\ NASA
}

\section{SPONSORING/MONITORING} REPORT NUMBER

NASA/TM-2007-214935

\section{DISTRIBUTION/AVAILABILITY STATEMENT}

Unclassified-Unlimited

Subject Category: 71

Available electronically at http://gltrs.grc.nasa.gov

This publication is available from the NASA Center for AeroSpace Information, 301-621-0390

\section{SUPPLEMENTARY NOTES}

\section{ABSTRACT}

Three different types of diagnostic data-blade surface flow visualization, shroud unsteady pressure, and laser Doppler velocimeter (LDV)--were obtained on two fans, one forward-swept and one aft-swept, in order to learn more about the shocks which propagate upstream of these rotors when they are operated at transonic tip speeds. Flow

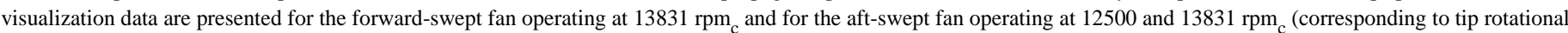
Mach numbers of 1.07 and 1.19, respectively). The flow visualization data identify where the shocks occur on the suction side of the rotor blades. These data show that at the takeoff speed, $13831 \mathrm{rpm}_{\mathrm{c}}$, the shocks occurring in the tip region of the forward-swept fan are further downstream in the blade passage than with the aft-swept fan. Shroud unsteady pressure measurements were acquired using a linear array of 15 equally-spaced pressure transducers extending from two tip axial chords upstream to 0.8 tip axial

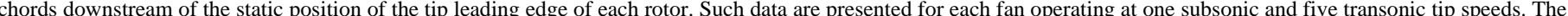

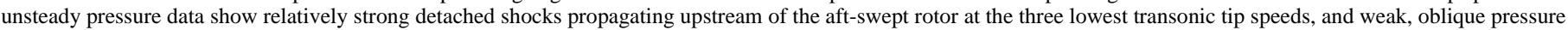

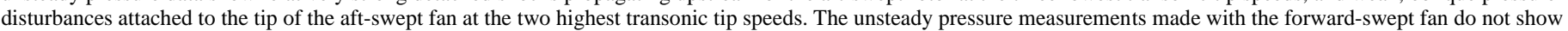
strong shocks propagating upstream of that rotor at any of the tested speeds. A comparison of the forward-swept and aft-swept shroud unsteady pressure measurements indicates that at any given transonic speed the pressure disturbance just upstream of the tip of the forward-swept fan is much weaker than that of the aft-swept fan. The LDV data suggest that at 12500 and $13831 \mathrm{rpm}_{\mathrm{c}}$, the forward-swept fan swallowed the passage shocks occurring in the tip region of the blades, whereas the aft-swept fan did not. Due to this difference, the flows just upstream of the two fans were found to be quite different at both of these transonic speeds. Nevertheless, despite distinct differences just

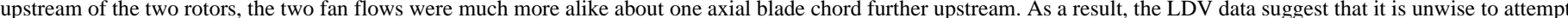

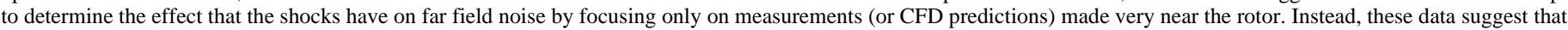
it is important to track the shocks throughout the inlet.

15. SUBJECT TERMS

Multiple pure tone noise; Laser velocimetry; Shocks; Acoustics; Turbofan; Forward-swept fan

\section{SECURITY CLASSIFICATION OF:}

a. REPORT

$\mathrm{U}$ b. ABSTRACT U

\begin{tabular}{l|l}
\multicolumn{1}{l|}{$\begin{array}{l}\text { 17. LIMITATION OF } \\
\text { PABSTRACT } \\
\text { PAGE }\end{array}$} & UU \\
\hline
\end{tabular}

18. NUMBER
OF
PAGES
27

19a. NAME OF RESPONSIBLE PERSON STI Help Desk (email:help@sti.nasa.gov) 19b. TELEPHONE NUMBER (include area code) 301-621-0390 

